\title{
Surveiller le territoire des cités d'Asie Mineure aux époques hellénistique et impériale : aspects administratifs, financiers et fiscaux
}

\author{
Cédric BRÉLAZ*
}

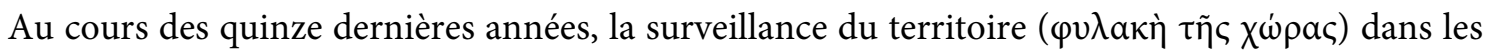
cités grecques a fait l'objet de deux études de synthèse, l'une consacrée aux moyens dévolus à cette activité par les rois aussi bien que par les cités au cours de l'époque hellénistique ${ }^{1}$, l'autre s'attachant à ce qu'il en était durant la période impériale, à une époque où les armées civiques avaient été abolies à la suite de l'affirmation de la souveraineté de Rome dans le domaine militaire ${ }^{2}$. Dans l'intervalle, plusieurs nouveaux documents ont été publiés qui permettent d'en examiner plus particulièrement les aspects administratifs, financiers et fiscaux. Le présent article se propose, dans un premier temps, de reprendre, à la faveur de la publication d'une nouvelle inscription provenant de la petite cité thessalienne de Doliché et grâce à un extrait de Polyen qui peut être versé au dossier, la discussion de documents d'Asie Mineure d'époque hellénistique relatifs à cette question, déjà connus mais d'interprétation délicate et, parfois, controversée, au premier chef certaines clauses du traité d'isopolitie entre Milet et Héraclée du Latmos. Dans un second temps, l'article s'interrogera, sur la base d'une dizaine d'inscriptions et de poids récemment publiés d'Asie Mineure et en particulier d'un riche dossier provenant de la cité de Hiérapolis en Phrygie, sur les modalités de financement de ce service d'intérêt public dans les cités grecques à l'époque impériale et sur le statut de la charge de paraphylaque qui y était spécialement affectée ; ce sera aussi l'occasion d'examiner les implications économiques des activités des paraphylaques dans les campagnes, qui comportent des facettes contradictoires, et de discuter l'hypothèse, souvent avancée dans la recherche, des attributions fiscales des titulaires de cette fonction. Enfin, on reviendra, dans une troisième et dernière partie, sur la question non encore entièrement élucidée des circonstances ayant présidé à l'introduction de la charge de paraphylaque dans les cités d'Asie Mineure au cours du ${ }^{\text {er }}$ s. p.C.

\footnotetext{
* Prof. Dr. Cédric Brélaz, Université de Fribourg, Institut du monde antique et byzantin, Rue PierreAeby 16, CH-1700 Fribourg, Suisse (cedric.brelaz@unifr.ch ; (1) https://orcid.org/0000-0001-8170-2140).

Des versions préliminaires de cette étude furent présentées à la Maison de l'Orient et de la Méditerranée Jean Pouilloux à Lyon dans le cadre du Séminaire de recherche du Laboratoire HiSoMA à l'invitation de J. Aliquot et de J.-B. Yon ainsi que lors du 17. Schweizer Epigraphisches Treffen organisé à Berne par $M$. Aberson. Mes remerciements vont aux organisateurs et participants de ces rencontres, en particulier à R. Bouchon, V. Chankowski, B. Helly, J. Nelis-Clément et V. Walser, de même qu'aux experts anonymes de la revue, pour leurs précieuses suggestions et remarques.

${ }^{1}$ Chaniotis 2008.

${ }^{2}$ Brélaz 2005.
} 


\section{La surveillance du territoire dans les cités grecques à l'époque hellénistique : organisation admi- nistrative, implications financières et attributions fiscales d'un service d'intérêt public}

Explicitement identifiée comme un champ d'action des cités grecques depuis le IV ${ }^{\mathrm{e}}$ s. a.C., la $\varphi v-$

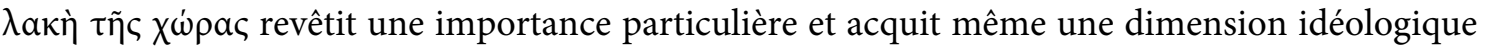
au cours de l'époque hellénistique, tandis que l'autonomie des cités était menacée par le pouvoir éminent des rois. En plus des impératifs liés à la défense des citoyens et de leurs biens et indépendamment de son utilité pratique, la surveillance territoriale devint pour les cités une façon d'affirmer leur souveraineté, d'où les nombreuses initiatives prises par celles-ci pour organiser ce service et pour célébrer ceux qui s'en acquittaient. Ces différentes mesures ont été examinées par A. Chaniotis dans une étude de référence sur la question ${ }^{3}$. Chose intéressante, les rois hellénistiques participèrent activement à la mise sur pied de structures dévolues à la défense du territoire à l'échelon local, en recourant notamment à des troupes de mercenaires stationnées sur le territoire des cités se trouvant dans un rapport de subordination avec eux ainsi qu'en favorisant l'implantation de groupes de soldats et la fondation de colonies militaires dans les régions étant passées sous leur obédience ${ }^{4}$. Tout en veillant à présenter leurs efforts comme une contribution à la protection des cités, la défense du territoire fut, pour les rois, un moyen de contrôler l'espace et un instrument de leur domination. Au sein de l'organisation militaire et administrative de plusieurs royaumes hellénistiques, des troupes furent, par ailleurs, spécialement affectées à la surveil-

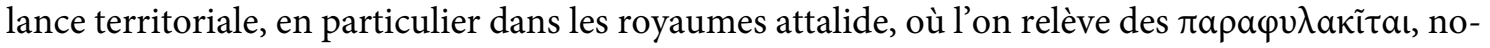
tamment sur le territoire de la cité de Pergame, et surtout lagide, où sont attestés des contingents

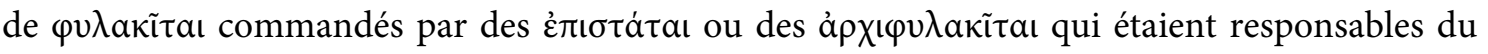
maintien de l'ordre à travers la chôra égyptienne ${ }^{5}$. Quant aux structures proprement civiques, la défense du territoire reposait sur des réseaux de fortins disposés à travers la chôra ${ }^{6}$, ainsi que sur

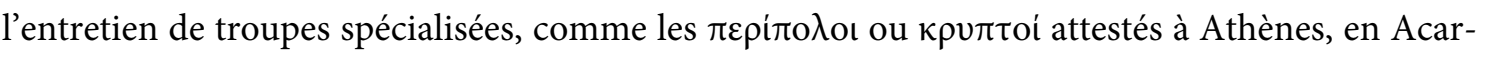
nanie ou en Illyrie, qui étaient le plus souvent formées de citoyens plutôt que de mercenaires? Certaines cités jouissant d'un vaste territoire, telles qu'Athènes ou Rhodes, nommaient même annuellement des magistrats militaires chargés expressément de cette tâche et portant le titre de

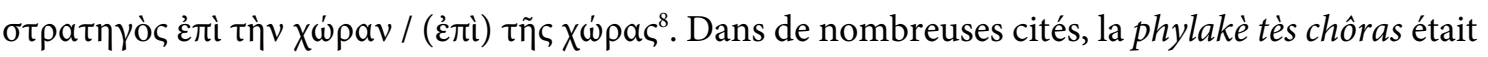

\footnotetext{
${ }^{3}$ Chaniotis 2008.

${ }^{4}$ Pour les colonies militaires, voir l'exemple de l'établissement de Toriaion en Phrygie : Savalli-Lestrade 2018. Pour les formes de l'occupation militaire antigonide de l'Attique, voir Oetjen 2014.

${ }^{5}$ Brélaz 2005, 125-129; Bauschatz 2013 ; Fischer-Bovet 2014.

${ }^{6}$ Voir par exemple Fachard 2012.

${ }^{7}$ Couvenhes 2011.

${ }^{8}$ À Rhodes, cette magistrature avait en charge la défense du territoire insulaire, non des possessions continentales de la cité pour lesquelles existait un commandement spécifique. C'est néanmoins sous l'influence des institutions rhodiennes que la stratégie du territoire fut adoptée par plusieurs cités de Carie au cours de l'époque hellénistique : Brélaz 2005, 75-77 ; SEG LIV 1020, 3 ; SEG LXIV 934. Le maintien de cette magistrature au cours de la période impériale à Aphrodisias et à Iasos (SEG LXIV 936) suggère que cette fonction put conserver des compétences dans le domaine de la surveillance territoriale à cette époque, d'autant que le magistrat iasien fut précisément commémoré dans la chôra : voir Boulay - Pont 2014, 30-31.
} 
une des tâches normalement confiées aux organisations éphébiques ${ }^{9}$. Par ailleurs, en cas d'urgence, les cités pouvaient s'assurer le concours de la population locale en ordonnant une levée en masse des citoyens aussi bien que des résidents étrangers ${ }^{10}$. Sans même parler de la construction et de l'entretien des fortins, l'organisation d'un service de défense du territoire était pour elles une opération coûteuse, en particulier lorsque cela supposait d'engager des mercenaires. Le recrutement de citoyens engendrait également des frais car les garnisaires recevaient une indemnité et pouvaient être équipés par la cité ${ }^{11}$. À défaut de structure pérenne qui aurait contraint les citoyens à contribuer à la défense du territoire sans recevoir de dédommagement, les cités, de même que les rois, furent contraintes d'envisager diverses solutions pour financer des services relevant de la phylakè tès chôras. C'est ce que nous examinerons dans la première partie de cette étude.

\subsection{Le service de surveillance du territoire: une prestation donnant droit à une exemption fiscale}

Une lettre fragmentaire publiée en 1979 par M. Wörrle, émanant, au début du II ${ }^{\mathrm{e}}$ s. a.C., d'un roi dont le nom n'a pas été conservé mais dans lequel il convient de reconnaître vraisemblablement Eumène II, énumère une série de privilèges qui furent concédés à une communauté rurale, visiblement nommée Philotéra, située sur le territoire de la cité lycienne de Telmessos ${ }^{12}$. On y apprend que les habitants bénéficièrent de diverses exemptions. Ceux-ci furent notamment libérés de l’impôt en nature consistant à fournir du fourrage destiné aux montures de la cavalerie royale ainsi que, pour une durée de dix ans, de l'obligation d'héberger des troupes. Ces mesures furent prises par le roi en vue de s'attacher la loyauté des habitants et, surtout, d'encourager l'installation de nouveaux groupes de personnes dans la communauté rurale en question. Dans cette perspective, le roi veilla à ce que "soient exemptés de la taxe sur l'artisanat les artisans venant s'établir qui assumeraient le service de surveillance des confins (

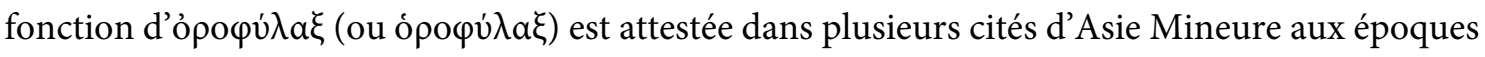
hellénistique et impériale. Suivant que l'on comprend le premier élément du composé au sens de

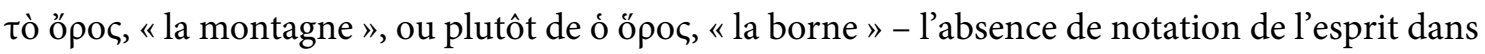
les inscriptions empêchant de faire la distinction nécessaire -, on y verra un "garde des montagnes » ou, à l'inverse, un « garde des frontières ». Bien que L. Robert se soit résolument prononcé en faveur de la première interprétation, il convient d'admettre que les documents à notre disposition ne nous autorisent pas à trancher de manière définitive ${ }^{14}$. C'est pourquoi nous maintien-

\footnotetext{
${ }^{9}$ Chankowski 2011, 344-366 ; Kennell 2012.

${ }^{10}$ C'est ce qui produisit, par exemple, à Cos à l'époque de la première guerre crétoise (205-200 a.C.) où un certain Dioklès organisa la résistance du territoire face aux incursions ennemies (IG XII 4/1 98, 1. 10-13).

${ }^{11}$ Boulay 2014, 56-73. Il en alla de même à Priène où, pour libérer le territoire civique dans le contexte des invasions galates, on aligna, en plus des volontaires, des fantassins et des cavaliers qui étaient des

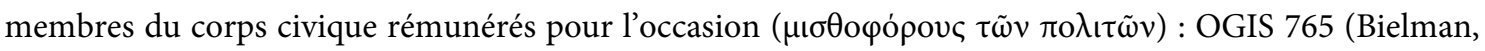
Retour à la liberté, 86-90 no. 22, 1. 15-25).

12 Wörrle 1979 (SEG XXIX 1516) ; cf. J. et L. Robert, BE 1980, 484.

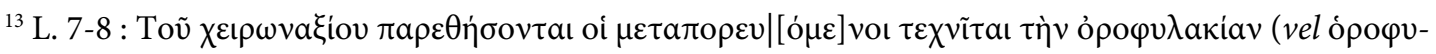
$\lambda$ 入kíav) aipó $\mu \varepsilon[v o l]$.

${ }^{14}$ Robert 1983a, 101-109. Fait exception un règlement de Chios du milieu du V $\mathrm{V}^{\mathrm{e}}$ s. a.C. où il est fait

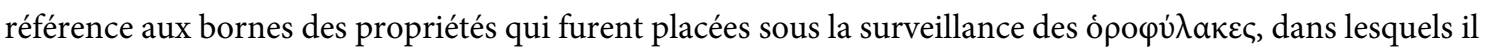
convient, par conséquent, de reconnaître des magistrats chargés de faire respecter les limites foncières
} 
drons volontairement l'ambiguïté en transcrivant ici le titre sous la forme (h)orophylaque et parlerons, à propos de cette fonction, de la surveillance des confins de manière générale, les zones limitrophes des cités coïncidant, du reste, le plus souvent avec des régions faites de montagnes, collines et maquis ${ }^{15}$.

On comprend, dans le cas présent, que le roi chercha à faire croître la communauté rurale située dans l'arrière-pays de Telmessos et à lui faire jouer un rôle de défense territoriale. À défaut d'y installer une garnison, le roi s'efforça de trouver une solution économique lui permettant, sinon d'assurer un contrôle militaire direct de la zone en question, du moins d'organiser un service de patrouilles territoriales contribuant à la sécurité de la contrée. Cette exigence revêtait une importance d'autant plus grande pour les Attalides que la région leur avait été récemment acquise en vertu du traité d'Apamée et qu'il s'agissait pour eux d'y imposer leur autorité. Des mesures analogues furent prises par Eumène II à un autre point du territoire de Telmessos, dans le village des Kardakoi, où le roi concéda pareillement des exemptions fiscales aux habitants et aux gens qui viendraient s'y installer en vue de repeupler l'établissement, à condition que ceux-ci prennent à leur charge la remise en l'état de la fortification ${ }^{16}$. Au contraire des cas où, dans les années 270 a.C., Philétairos avait financé directement des services de surveillance territoriale dans les cités de Cyzique et de Kymè en en supportant les frais ou en fournissant des armes ou des chevaux $^{17}$, ces exemptions présentaient l'avantage de ne pas grever le budget royal et constituèrent, tout au plus, un manque à gagner. Indépendamment des initiatives royales, la question du financement de la défense du territoire donna lieu, à l'époque hellénistique, à des initiatives originales de la part des cités elles-mêmes.

\subsection{La mise à ferme de la surveillance du territoire}

Le traité de paix et d'isopolitie entre Milet et Héraclée du Latmos, publié en 1914 par A. Rehm, comporte diverses clauses visant à rétablir les relations entre les deux cités qui s'étaient affrontées dans les années 180 a.C. ${ }^{18}$. Celles-ci concernent notamment l'entraide militaire, l'échange de citoyennetés entre les ressortissants des deux parties contractantes, les conditions présidant aux échanges commerciaux ainsi que la résolution des litiges qui étaient en cours dans les régions frontalières. C'est dans ce contexte qu'il est fait mention des institutions chargées dans les deux cités de la surveillance de leur territoire respectif. Il est prévu, en particulier, que des (h)orophylaques interviennent pour le cas où des esclaves fugitifs seraient capturés (1. 89) :

(Haussoullier 1879, 230-241 no. II, A, 1. 6-9 [SGDI 5653] ; republication par Faraguna 2005). La situation est différente en Égypte où de nombreux papyrus mentionnent des gardes appelés ỏ $\rho \varepsilon о \varphi v ́ \lambda a \kappa \varepsilon \varsigma$, avec cette

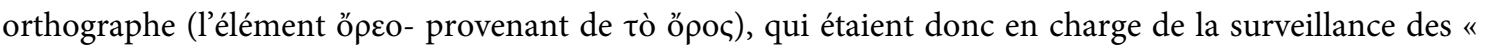
montagnes », dans ce cas du relief désertique bordant la vallée du Nil : voir Hennig 2006.

${ }^{15}$ Brélaz 2005, 157-171. Pour sa part, Chankowski 2011, 347-359, se prononce en faveur des « gardes des montagnes ». Cf. Kayser 2011.

${ }^{16}$ Maier, Mauerbauinschriften, no. 76 ; voir Virgilio 2001.

${ }^{17}$ OGIS 748 ; SEG L 1195 ; voir Virgilio 2016.

${ }^{18}$ I.Delphinion 150 (Syll. ${ }^{3}$ 633) avec la traduction et le commentaire de P. Herrmann dans I.Milet, VI/1, p. 185-189 no. 150. Pour le contexte historique, voir Rousset 2019, 113-115. 


\begin{abstract}
« Les esclaves s'étant enfuis de Milet à Héraclée ou d'Héraclée à Milet qui auront été

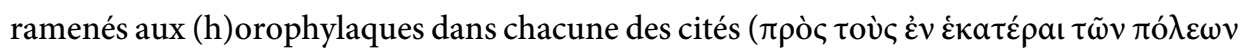

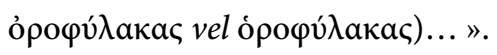

La suite des dispositions (1. 90-96) stipule que la capture des esclaves s'étant échappés de la cité voisine devait être signifiée sous dix jours aux principaux magistrats de la cité où avait eu lieu

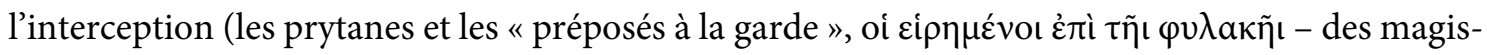
trats originellement en charge de la surveillance territoriale, mais dont les compétences politiques et administratives étaient bien plus étendues -, à Milet ${ }^{19}$; les prostates à Héraclée), lesquels se chargeraient d'avertir leurs homologues. Le traité prévoit encore un dédommagement au profit des (h)orophylaques (1. 96-99) :

« que la restitution aux propriétaires des esclaves de chaque cité ait lieu après le versement aux (h)orophylaques d'une rétribution s'élevant à douze anciennes drachmes de Rhodes par esclave pour la restitution et d'une obole par jour pour la nourriture, au plus tard dans les quatre mois depuis que la lettre a été adressée aux magistrats; sinon, que (les esclaves) reviennent comme propriété aux (h)orophylaques».

Étrangement, alors que le même mot ỏ pour désigner les (h)orophylaques des deux cités, deux expressions différentes sont employées aux 1. 90 et 93-94 lorsqu'il est question de la procédure qu'il s'agira de suivre pour alerter les magistrats civiques :

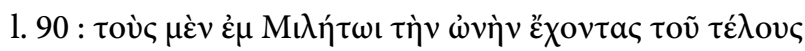

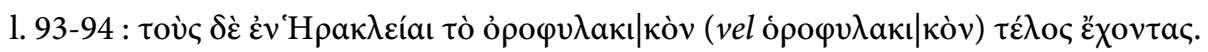

Ces expressions ont donné lieu à diverses interprétations dont aucune n'est toutefois parvenue, jusqu'à ce jour, à rendre compte du problème dans sa totalité. Trois questions principales méritent, en l'espèce, d'être soulevées : comment faut-il comprendre le mot $\tau \varepsilon ́ \lambda$ oৎ qui apparaît dans les deux expressions ? Les personnages auxquels il est fait allusion aux 1.90 et 93-94 doivent-ils être identifiés avec les (h)orophylaques mentionnés à la 1.89 d'abord, puis à nouveau aux 1.97 et 99 ? Enfin, quelles étaient les prérogatives des différents protagonistes prenant part à l'organisation du service de surveillance territoriale à Milet, d'une part, et à Héraclée, de l'autre ?

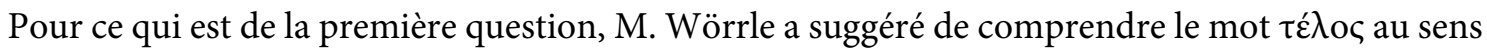

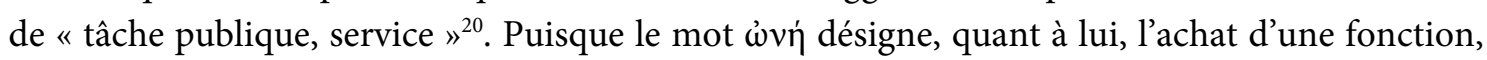
telle une prêtrise, ou d'un service public consécutivement à un affermage et, par extension, le contrat d'affermage lui-même ${ }^{21}$, P. Herrmann, dans le sillage de M. Wörrle, a proposé les traductions suivantes des deux expressions en les commentant par la même occasion : « diejenigen (Unternehmer), die diese Aufgabe durch Kauf (d. h. öffentliche Vergabe auf vertraglichem Wege) übernommen haben » (1.90) pour ce qui est de Milet et « diejenigen, die in Herakleia die Aufgabe des Wachdienstes in den Bergen (vertraglich) übernommen haben $»(1.93-94)^{22}$. Pourtant, le sens

\footnotetext{
${ }^{19}$ Müller 1976, 39-57.

${ }^{20}$ Wörrle 1979, 98-102.

${ }^{21}$ Cf. Helly - Tziafalias 2013, 177 n. 81.

22 P. Herrmann dans I.Milet, VI/1, p. 188.
} 


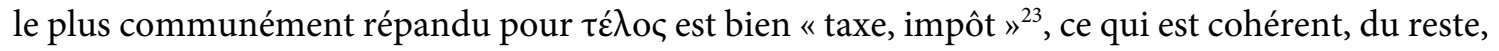
avec le champ lexical dont relève le mot $\omega$ vń, comme le montre la clause suivante de la même convention $^{24}$. Par conséquent, il est sans doute préférable de comprendre, dans la première tour-

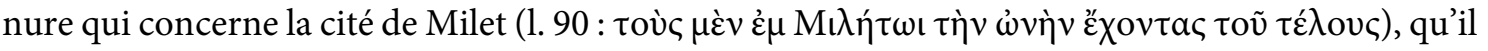
est ici question de " ceux qui ont la ferme de l'impôt », pour reprendre la traduction qu'avaient proposée J. et L. Robert ${ }^{25}$. Dans cette logique, les (h)orophylaques auraient fait office, en même temps, de collecteurs d'impôts, plus particulièrement des taxes douanières qui étaient perçues aux frontières du territoire civique ainsi que des autres taxes liées à l'exploitation des terres publiques périphériques, comme la pâture. La levée de ces taxes aurait donc permis aux (h)orophylaques de couvrir les frais qu'ils avaient dû avancer pour remporter l'adjudication de cette fonction et de faire des profits. C'est l'interprétation qui a été retenue en dernier lieu par A. Chaniotis ${ }^{26}$.

Cependant, il convient de remarquer que si les expressions retenues aux 1. 90 et 93-94 diffèrent du titre d'(h)orophylaque et si l'on a pris soin de les distinguer, c'est certainement que la fonction des individus en question était, elle aussi, différente ${ }^{27}$. Les deux expressions ne sauraient être considérées comme des périphrases servant à préciser en quoi consistait une partie des compétences des (h)orophylaques. Les personnes décrites aux 1. 90 et 93-94 étaient, certes, liées aux (h)orophylaques - puisqu'il en est question à propos de la remise aux (h)orophylaques des esclaves fugitifs qui seraient capturés -, mais elles ne se confondaient pas avec eux. À Milet, comme nous l'avons $\mathrm{vu}$, ces personnes semblent avoir été des fermiers de l'impôt ${ }^{28}$. Le fait que fermiers de l'impôt et (h)orophylaques aient été, pour les besoins de leurs missions respectives, actifs dans les mêmes portions du territoire civique pourrait expliquer qu'ils aient eu à collaborer ici, dans le cadre de la procédure de déclaration de la capture d'esclaves fugitifs. L'expression servant, à Héraclée, à désigner la fonction correspondant à celle des fermiers de l'impôt à Milet permet d'entrevoir plus précisément les liens entre les uns et les autres : on y parle de « ceux qui, à Héraclée, sont en

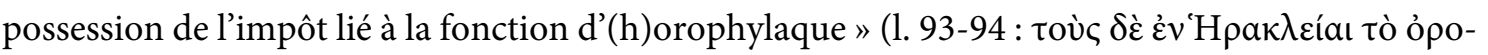

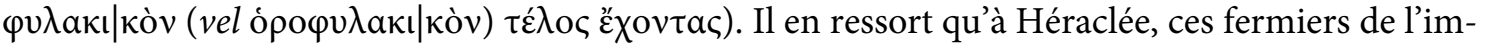

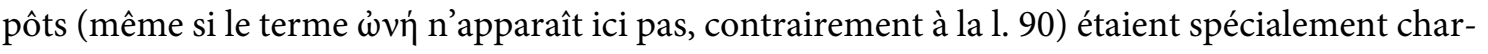

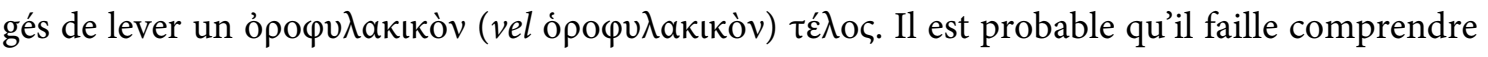

\footnotetext{
${ }^{23}$ Cela fut relevé à raison par Piejko 1988, 107 n. 34.

${ }^{24}$ Les mêmes termes servent à décrire, aux 1. 99-104, le péage pour le passage en bateau à travers le golfe

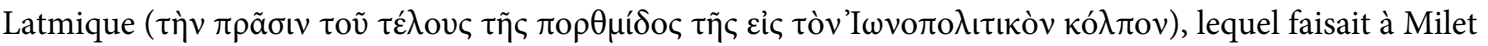

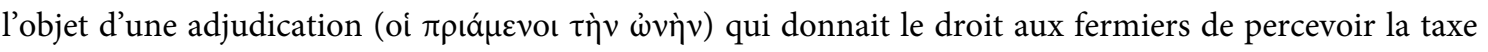
( $\pi \rho a ́ \xi o v \sigma \iota v)$.

${ }^{25}$ Robert 1983a, 102. Haussoullier 1917, 38-40, traduisait « les fermiers de la douane ».

${ }^{26}$ Chaniotis 2008, 139-141.

${ }^{27}$ Nous révisons ici l'opinion initialement exprimée dans Brélaz 2005, 162 ; voir la discussion suivant la contribution de Chaniotis 2008, 151-152.

${ }^{28}$ Dans son commentaire à I.Delphinion 150, A. Rehm voyait dans ces personnes des $\tau \varepsilon \lambda \tilde{\omega} v a \mathrm{l}$, dont les (h)orophylaques auraient été des employés ; en revanche, il ne distinguait pas les (h)orophylaques des individus mentionnés aux 1. 93-94 à Héraclée.
} 
ici la taxe servant à financer le service de surveillance territoriale confié aux (h)orophylaques ${ }^{29}$. Cette pratique consistant à donner à une taxe le nom du service que celle-ci permettait de financer, en particulier dans le domaine du maintien de l'ordre, était répandue en Égypte aux époques hellénistique et impériale ${ }^{30}$. On en déduit qu'à Héraclée, les fermiers de la taxe pour le service d'(h)orophylaque étaient responsables de sa gestion et qu'ils étaient peut-être même chargés d'en recruter et défrayer les gardes.

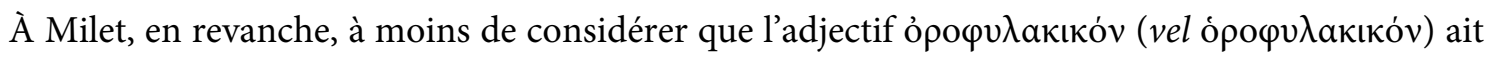

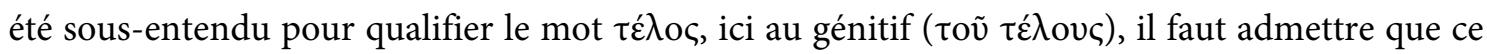
sont les fermiers de l'impôt en général, sans autre précision, qui étaient tenus d'intervenir. Du moment qu'ils étaient en relation avec les (h)orophylaques, ces fermiers devaient néanmoins nécessairement contribuer, d'une manière ou d'une autre, à la gestion du service de surveillance territoriale, comme à Héraclée. Une partie des taxes qu'ils levaient pouvait éventuellement, dans ce cas aussi, venir financer ce service. La différence dans l'expression retenue dans le traité de paix entre Milet et Héraclée pour désigner ces individus - lesquels paraissent avoir revêtu des fonctions analogues dans les deux cités et se trouver dans un rapport similaire avec les (h)orophylaques pourrait ainsi refléter la diversité des modalités d'attribution des contrats publics permettant le financement du service de surveillance territoriale dans l'une et l'autre cité. En l'occurrence, les expressions reproduites aux 1.90 et 93-94 correspondraient au libellé sous lequel étaient désignés, respectivement à Milet et à Héraclée, les fermiers de l'impôt responsables du financement de la fonction d'(h)orophylaque.

Dans tous les cas, les (h)orophylaques, que ce soit à Milet ou à Héraclée, n'étaient pas des magis-

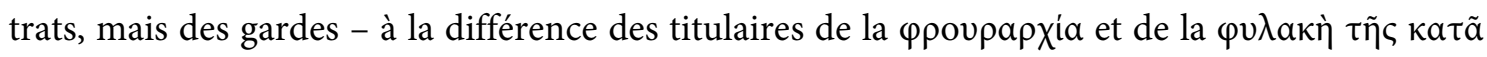

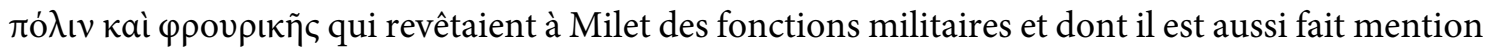
dans la même convention (1. 50-52). S’ils pouvaient être amenés à appréhender des esclaves fugitifs (1. 87-90), il ne leur revenait pas, en tant que subordonnés, d'en avertir les principaux magistrats de la cité. Cette prérogative revenait à leurs supérieurs, aux individus qui avaient pris ce service à ferme et qui étaient autorisés, pour se rembourser, à lever une taxe spécifique, du moins à Héraclée. Indépendamment de ces impératifs de hiérarchie, une autre raison pourrait expliquer pourquoi les (h)orophylaques étaient tenus d'informer les individus responsables de l'organisation administrative du service de surveillance territoriale. C'est que, comme l'enseignent les dispositions énoncées aux 1. 96-99, la capture d'esclaves fugitifs avait des implications financières. Compte tenu de la rétribution que les propriétaires des esclaves repris étaient tenus de payer aux (h)orophylaques pour leur restitution ainsi que du dédommagement qui était versé à ces derniers pour l'entretien des esclaves durant leur captivité, les fermiers de l'impôt, en tant que personnes responsables du financement du service de surveillance territoriale, pouvaient être intéressés à exercer un contrôle sur ces transactions, sans toutefois que l'on puisse établir si une part des montants versés aux (h)orophylaques était prélevée par eux dans un second temps. Quoi qu'il en soit des détails de la gestion financière du service de surveillance territoriale dans les deux cités, le

\footnotetext{
${ }^{29}$ Cette explication avait déjà été entrevue par Rostovtzeff 1941, II, 669, qui considérait néanmoins que les (h)orophylaques étaient eux-mêmes chargés de la collecte de cette taxe et que celle-ci était combinée avec une taxe douanière.

${ }^{30}$ Homoth-Kuhs 2005.
} 
traité entre Milet et Héraclée du Latmos ne permet pas de prouver positivement que les (h)orophylaques étaient eux-mêmes chargés de lever des taxes aux limites de la chôra ${ }^{31}$. Cela n'exclut toutefois pas que, dans les faits, les (h)orophylaques aient été appelés à seconder les fermiers de l'impôt et leurs agents dans la perception des taxes dont une partie du produit était manifestement affectée à leur entretien.

\subsection{Surveillance du territoire et perception fiscale}

La mise à ferme de la surveillance du territoire et la pratique conjointe d'opérations consistant à patrouiller dans la chôra et à lever des impôts apparaissent dans une anecdote rapportée par Polyen à propos d'événements censés s'être déroulés en Thessalie au début du IV ${ }^{\mathrm{e}} \mathrm{s}$. a.C. Le principal protagoniste en est un certain Deinias, originaire de Phères, qui, à en croire Polyen, s'empara du pouvoir à Krannon de la façon suivante :

"Les gens de Krannon affermaient la garde de la cité. Deinias la prit à ferme et s'acquitta de la garde durant trois ans de la manière la plus scrupuleuse qui fût, de sorte que, pour ceux qui sortaient à une heure avancée, la nuit était encore plus sûre que le jour. Étant loué pour cela, il engagea toujours plus de gardes afin de gagner encore en estime grâce au renforcement de la surveillance. Comme la cité mettait à ferme la dîme sur le blé, il envoya son plus jeune frère prendre à ferme les taxes, en dépassant de beaucoup (par son offre) le revenu (attendu). Ayant ainsi fait nommer son frère percepteur de la dîme dans le territoire et lui ayant confié de nombreux jeunes gens vigoureux, à la fois patrouilleurs des villages et collecteurs des céréales qui étaient soumises à la dîme, il profita de la fête qu'on appelle les Itônia, lors de laquelle tous les gens de Krannon s'amusent, pour mêler aux gardes se trouvant dans la ville les fermiers qui étaient loin de la ville et pour poster des hommes qui étaient demeurés sobres autour de gens avinés : c'est ainsi qu'après avoir fait tuer plus de mille citoyens il devint tyran à Krannon ${ }^{32}$.

\footnotetext{
${ }^{31}$ La surveillance du territoire fit également l'objet d'une clause dans la convention passée, vers la même époque, entre les deux petites cités locriennes de Hypnia et Myania : F.Delphes III/4 352 (Choix Delphes, col. II, 1. 23-28; fin du III ${ }^{e}$ - début du II ${ }^{\text {e }}$ s. a.C.) ; voir Rousset 2002, 17, 160-162. On y précise que les

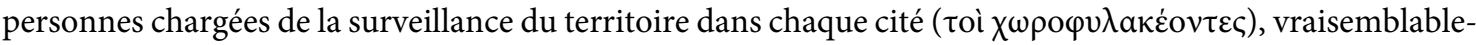
ment des citoyens formant une troupe que l'on pourrait comparer aux (sym)peripoloi attestés en Phocide voisine, bénéficieraient d'une exemption fiscale servant de compensation pour la mission qu'ils accomplissaient au profit de leur cité, ce qui fait songer au dispositif prévu par les Attalides pour le territoire de la cité de Telmessos décrit ci-dessus.

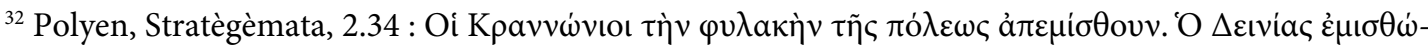

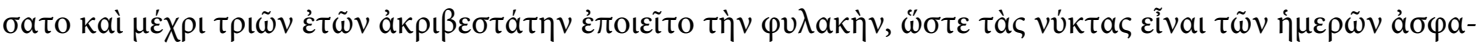

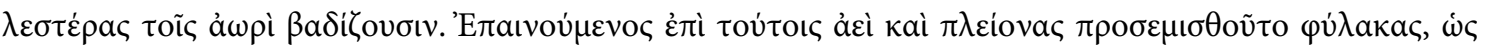

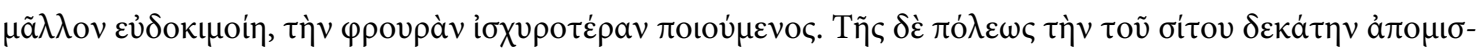

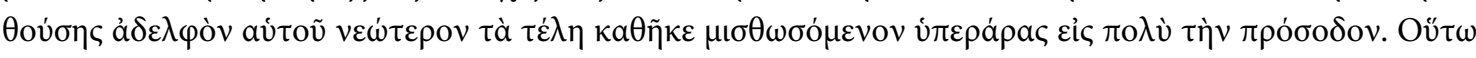

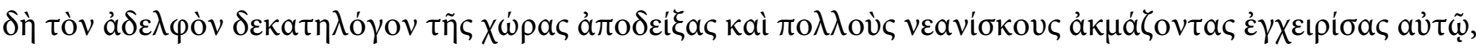

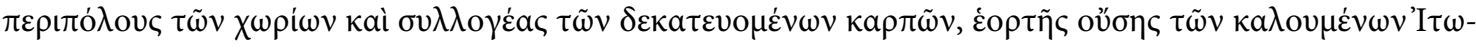

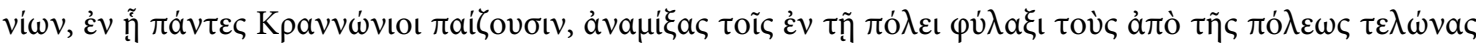

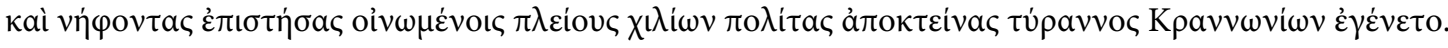


Cet épisode, quelle qu'en soit sa véracité pour ce qui est des détails, semble confirmer que la surveillance du territoire pouvait être affermée, visiblement pour plusieurs années dans ce cas. L'ensemble du lexique utilisé par Polyen pour décrire l'organisation de ce service dans la cité de Krannon est caractéristique des procédures d'adjudication, le verbe $\mu$ $\sigma \theta$ ó $\omega$ et ses composés en décrivant les différentes étapes, tant du point de vue de la collectivité qui mit à ferme le service

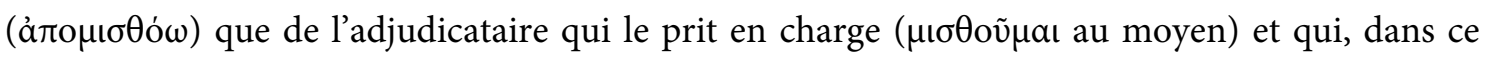
cadre, engagea accessoirement $\left(\pi \rho \circ \sigma \mu \sigma \theta\right.$ ó $\omega$ ) des employés pour s'en acquitter ${ }^{33}$; le préfixe $\pi \rho \circ \sigma-$ indique ici que l'adjudicataire, à côté du contrat principal d'affermage qui le liait à la collectivité, recruta à son tour des auxiliaires, en sous-traitant en quelque sorte le service dont il avait désormais l'exclusivité ${ }^{34}$. La perception de la dîme sur les récoltes céréalières suivait, elle aussi, à Krannon une procédure d'affermage, en tout point analogue à celle qui prévalait pour la surveillance

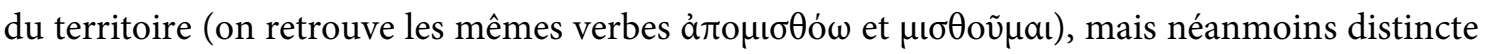
de celle-ci. En l'occurrence, c'est le frère de Deinias, que celui-ci poussa à se porter acquéreur, qui remporta l'adjudication. La réunion des deux tâches fut uniquement circonstancielle et due au fait que Deinias et son frère en vinrent à concevoir la surveillance du territoire et la collecte de la dîme comme une entreprise familiale conjointe, à des fins criminelles il se trouve. Les deux services furent, dans les faits, fusionnés : Deinias dota son frère d'une troupe de jeunes gens sur le modèle des gardes qu'il employait et ceux-ci agirent depuis ce moment à la fois comme patrouilleurs et comme percepteurs de la dîme dans les campagnes de la cité.

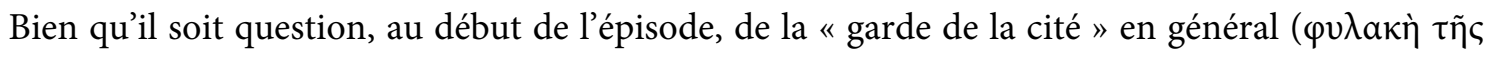
$\pi$ ó $\lambda \varepsilon \omega \varsigma$ ), il faut comprendre que les gardes exerçaient d'abord leur surveillance ( $\varphi \rho o u \rho \alpha ́$ ) dans la

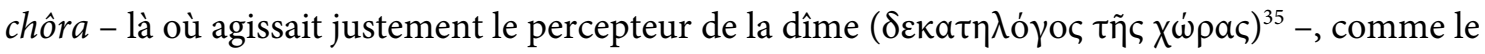
montre la suite du passage : les gardes effectuaient des patrouilles dans les villages ( $\pi \varepsilon \rho i \pi \circ \lambda$ o $\tau \tilde{\omega} v$ $\chi \omega \rho i \omega v)$. L'appellation $\varphi v \lambda \alpha \kappa \eta ̀ ~ \tau \tilde{\eta} \varsigma ~ \pi o ́ \lambda \varepsilon \omega \varsigma$ est ordinaire dans les cités grecques pour signifier que la surveillance du territoire intéressait la sécurité de l'ensemble de la communauté politique ${ }^{36}$. L'expression employée par Polyen à la fin de l'extrait, lorsqu'il est question de l'embuscade mise sur pied par Deinias lors de la fête des Itônia ${ }^{37}$, est, en revanche, plus alambiquée et prête à con-

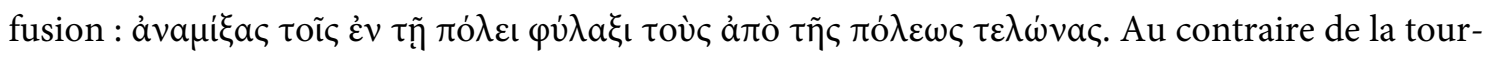

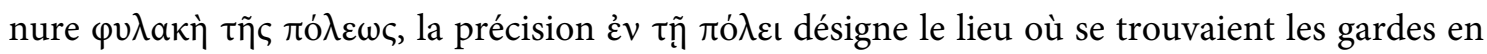
question : il convient donc ici de comprendre polis au sens géographique et de traduire "les gardes se trouvant dans la ville ». C'est parmi eux que Deinias demanda aux fermiers de la dîme de se fondre. La suite de la phrase révèle une structure en chiasme : les gardes stationnés dans la ville

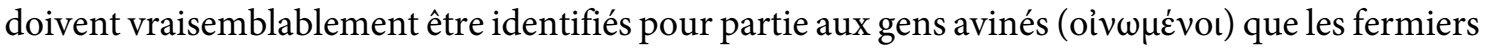
lancés par Deinias, restés sobres ( $\vee \eta ่ \varphi o v \tau \varepsilon \varsigma)$ quant à eux, réussirent à surprendre. Ce qui a retenu

\footnotetext{
${ }^{33}$ Sur ce vocabulaire, voir Pernin 2014, 485-488.

${ }^{34}$ Pour un autre composé dérivant du même verbe, cette fois-ci avec le préfixe $\pi \rho 0-(\pi \rho \circ \mu \sigma \theta \omega \tau \eta \dot{\zeta})$, désignant celui qui prend en location un service public, voir, toujours en Thessalie, SEG XXXIII 466 (Larissa, I ${ }^{\text {er }}$ s. a.C.) ; cf. I.Philippes II.1 222.

${ }^{35}$ Pour ce terme, voir Démosthène 23.177.

${ }^{36}$ Chaniotis 2008, 104 avec la discussion p. 147-148.

${ }^{37}$ L'identification du nom de la fête est rendu incertaine en raison des divergences de la tradition manuscrite à cet endroit, la lecture'I $\tau \omega v i$ i $\omega v$ étant une conjecture : pour les détails, voir Mili 2015, 229-233.
} 
l'attention de Polyen dans cette anecdote, à l'instar de nombreuses autres ruses de guerre compilées dans ses Stratègèmata, c'est la façon dont un groupe d'individus parvint à faire irruption dans la ville pour s'en emparer. Ces " gardes se trouvant dans la ville» doivent, par conséquent, être distingués des gardes du territoire recrutés par Deinias et correspondent aux sentinelles surveillant d'ordinaire les portes des villes ${ }^{38}$. Les hommes de Deinias sont, pour leur part, désignés ici sous l'appellation unique de «fermiers » (oi $\tau \varepsilon \lambda \omega ́ v a ı)$, car ceux-ci réunissaient aussi bien des patrouilleurs du territoire que des collecteurs des impôts depuis la fusion de ses troupes avec celles de son frère. Ces fermiers, qui étaient les agents du frère de Deinias, sont caractérisés comme étant ả $\pi$ ò $\tau \tilde{\eta} \varsigma \pi$ ó $\lambda \varepsilon \omega \varsigma$. Une telle formulation sert normalement à indiquer l'origine ou la provenance d'un individu ou d'un groupe « venant de la cité/de la ville» dont il est question ${ }^{39}$. Mais, dans ce contexte, la précision ảं qui concerne les gardes urbains : la préposition exprime donc ici, plutôt que l'origine, la distance et l'éloignement. Cette désignation des fermiers comme «étant loin de la ville » fut employée par Polyen pour signifier que ceux-ci étaient en principe actifs dans la chôra et pour rendre manifeste

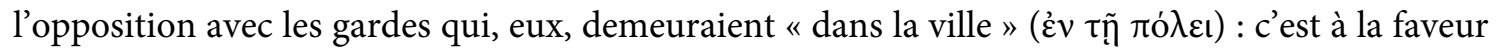
de l'attroupement provoqué par la célébration de la fête et des réjouissances que la bande armée de Deinias, qui venait de l'extérieur de la ville, parvint à pénétrer dans la ville, se fondre dans la foule, tromper la vigilance des sentinelles et accomplir son coup de force.

Il ressort de cette anecdote qu'en temps normal, les gardes du territoire n'étaient pas responsables, à Krannon, de la perception de la dîme sur les récoltes, pour laquelle on procédait à un affermage séparé ${ }^{40}$. On peut concevoir, toutefois, que la surveillance du territoire donnait lieu à la perception d'une taxe. Car Polyen, dans le cas de la cité de Krannon, ne dit rien des avantages que l'adjudicataire pouvait tirer de ce service, pour lequel il avait néanmoins dû nécessairement verser une somme, comme pour toute mise à ferme. Le meilleur exemple en est la ferme des taxes ( $\tau \grave{\alpha} \tau \dot{\varepsilon} \lambda \eta)$

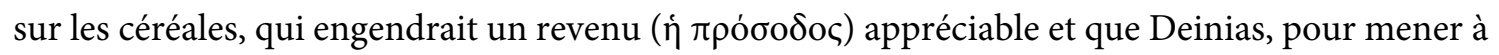
bien son plan, veilla à remporter en offrant un prix bien supérieur aux profits normalement attendus. On peut donc imaginer à Krannon un sytème voisin de celui en vigueur à Héraclée du Latmos au début du II ${ }^{\mathrm{e}}$ s. a.C. où, comme nous l’avons vu plus haut, ce service était financé par la levée d'une taxe spéciale, l' ỏ ferme. Réciproquement, la procédure de recrutement des (h)orophylaques à Héraclée et à Milet peut certainement être rapprochée de celle que l'on constate pour les gardes de Deinias à Krannon : ce sont les individus ayant pris à ferme la taxe sur la surveillance du territoire qui les engageaient. Le terme veavíко employé par Polyen pour décrire les jeunes gens qui constituaient la troupe de Deinias pourrait éventuellement faire songer aux associations éphébiques, mais le mode d'organisation du service de surveillance territoriale à Krannon tel que nous l'avons décrit, par le biais

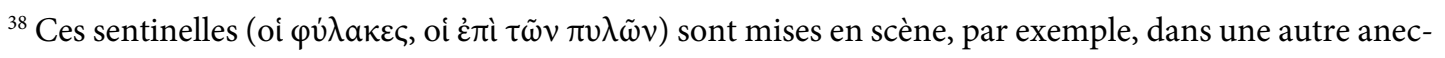
dote rapportée par Polyen, Stratègèmata, 2.35, et s'étant déroulée toujours en Thessalie, à Phères.

${ }^{39}$ Voir, par exemple, Thucydide 3.113.2 ; Polybe 5.70.8 ; Aelius Aristide. Or. 26.75 ; OGIS 737 ; SEG XXXIX 1710 ; I.Iasos 602.

${ }^{40}$ Chaniotis 2008, 138-139 avec la discussion p. 152-153.
} 
d'un affermage, dissuade d'y reconnaître des membres de ces groupes ${ }^{41}$. Les cités grecques, notamment en Thessalie, avaient encore d'autres façons de financer le recours à des jeunes gens pour surveiller leur territoire au cours de l'époque hellénistique.

\subsection{La surveillance du territoire comme service rémunéré}

Une longue inscription provenant de Doliché et datant de la fin du $\mathrm{II}^{\mathrm{e}}$ ou du milieu du $\mathrm{I}^{\mathrm{er}}$ s. a.C., dont A. Tziafalias et G. Lucas ont donné en 2012 une publication préliminaire, décrit le mode de financement du service de surveillance territoriale dans cette cité du nord de la Thessalie ${ }^{42}$. Malheureusement très fragmentaire (toute la partie droite de la pierre est manquante ainsi que le haut), le document n'autorise pas à présenter un texte suivi ni à reconstituer dans tous ses détails les mécanismes administratifs et financiers ayant présidé à l'opération. On y distingue cependant suffisamment de mots, ou de séquences de mots, pour en dégager le sens général. Bien que le début du texte ne soit pas préservé, on comprend qu'il s'agit de la copie d'un décret de la cité de

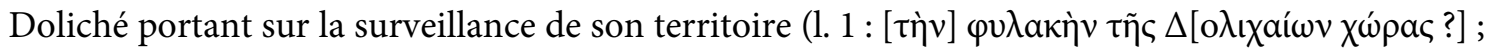

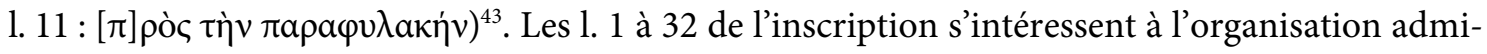
nistrative et financière du service, tandis que les 1.33 à 54 s'attachent à délimiter le territoire sur

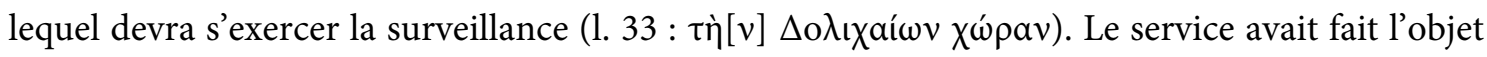
d'un contrat, qui énumérait explicitement les lieux sur lesquels devait porter la surveillance (1. 11-

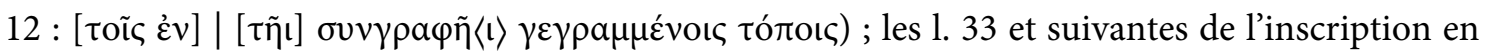
reproduisent vraisemblablement une portion. La personne chargée de fournir la prestation est un

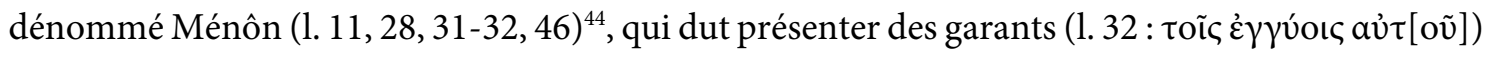
lors de la conclusion du contrat. Ces personnes se portaient certainement caution de Ménôn pour le cas où celui-ci aurait manqué aux obligations stipulées dans le contrat, qui pouvait prévoir une amende. Réciproquement, en cas de non-versement à Ménôn de la rémunération à laquelle il avait droit, les magistrats de la cité lui étaient réputés redevables du montant convenu (1. $32: \pi \rho a ́ \xi \mu$ i

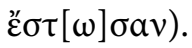

\footnotetext{
${ }^{41}$ Le terme veaviokol peut être également employé dans un sens non technique pour désigner, de manière générique, une troupe de soldats : voir Chankowski 2011, 253-264, 366-378. Voir cependant infra à propos de la petite troupe accompagnant un paraphylaque sous la conduite d'un néaniscarque sur le territoire d'Apollonia de la Salbakè.

${ }^{42}$ Tziafalias - Lucas 2012 (SEG LXII 367 ; vers 130-100 a.C.). Ci-dessous sont reproduites certaines des lectures que B. Helly et R. Bouchon réservent à leur réédition de l'inscription (à paraitre dans le futur Corpus des inscriptions de la Tripolis (Thessalie)), qu'ils préfèrent dater du milieu du Ir s. a.C., après l'introduction du « nouveau calendrier » thessalien qui semble employé dans le document. Je remercie vivement mes collègues lyonnais de m'avoir libéralement donné accès à leur documentation avant publication.

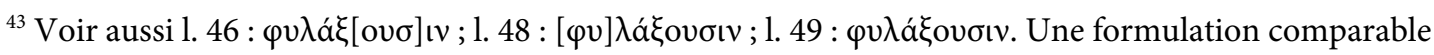
se lit dans une inscription fragmentaire du $\mathrm{II}^{e}$ s. a.C. reproduisant les clauses d'une convention entre les cités thessaliennes de Trikka et de Métropolis à la suite d'un différend frontalier : SEG LVII 533 adn (1. 10 :

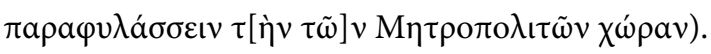

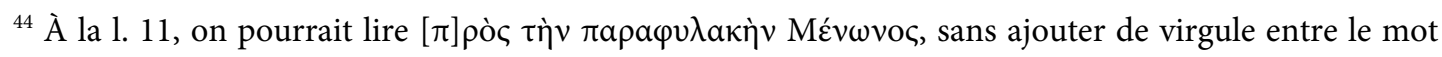
désignant le service et le nom de Ménôn comme le font les premiers éditeurs : il faudrait alors comprendre qu'était désignée ici spécifiquement la tâche de surveillance confiée à ce dernier.
} 
Pour ce qui est du financement de la paraphylakè, l'inscription mentionne à plusieurs reprises des versements de divers montants $(1.6: \delta \mathrm{i} \delta \text { ó } \tau \omega \sigma \alpha v)^{45}$, s'échelonnant par périodes de trois mois (1. 9 : $\dot{\varepsilon} \nu \tau \rho \mu \eta ́ v \omega \iota)^{46}$. Il est question, dans ce contexte, de personnes issues de différentes classes d'âge on mentionne des « adultes» $(1.5:[\dot{\varepsilon} v] \eta \lambda \hat{i} \kappa \omega \nu ; 1.6:[\tau \tilde{\omega}] \nu \dot{\varepsilon} v \eta \lambda \hat{i} \kappa \omega v)^{47}$-ainsi que d’une sélection d'un ou de plusieurs individus à la suite d'un tirage au sort de la part des tribus civiques

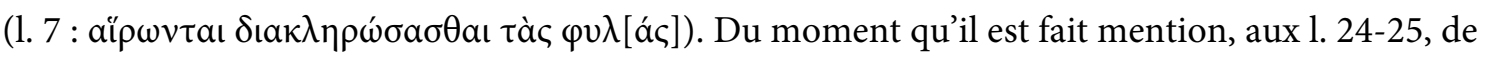

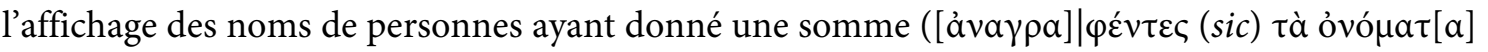

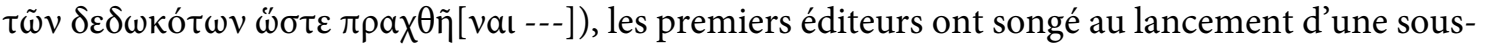
cription ou à la levée d'une contribution obligatoire dont les participants auraient été désignés à la suite d'un tirage au sort parmi les tribus civiques ${ }^{48}$. Les différentes occurrences du verbe $\delta i \delta \omega \mu \mathrm{t}$ (le plus souvent à l'impératif) ainsi que les deux « versements » dont il est question aux 1.20 et 22 s'appliqueraient, par conséquent, aux sommes à payer par les souscripteurs pour le financement de la surveillance territoriale. L'ensemble de la procédure était contrôlée par les principaux magistrats civiques, les tagoi, ainsi que par les trésoriers ${ }^{49}$ et donnait lieu à une reddition de comptes conformément aux lois de la citét ${ }^{50}$.

Les opérations financières semblent, en réalité, avoir été plus complexes encore, mais l'état lacunaire de l'inscription rend leur compréhension incertaine. Il est en effet aussi question, à plusieurs reprises dans l'inscription, de " personnes lésées ", notamment à la suite d'une condamnation (l.

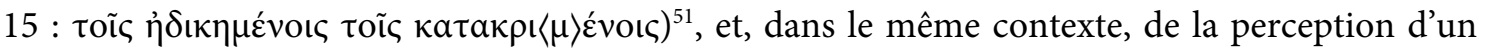
montant (l. 16: [ $\pi] \rho \alpha \sigma \varepsilon ́ \tau \omega)$. On reconnaît ici le même verbe que celui qui apparaît à propos de la liste de gens ayant fait un versement (1. 25 : $\omega \sigma \tau \varepsilon \pi \rho \alpha \chi \theta \tilde{\eta}[v \alpha \mathrm{l}---])$. Il se pourrait que Ménôn soit

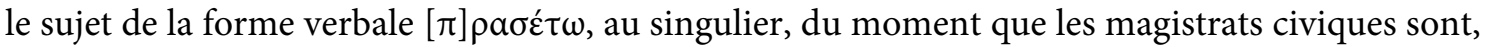
quant à eux, toujours cités au pluriel dans le document en tant que membres d'un collège. On pourrait éventuellement comprendre que Ménôn fut autorisé à lever des amendes (il est aussi fait mention de contrevenants dans le document ${ }^{52}$ ) ou, à défaut, que la résolution de litiges donna lieu à des versements ayant permis à la cité de financer en partie la surveillance du territoire. Il est aussi fait allusion à des sommes ou à des choses (peut-être des propriétés ?) qui devront être rendues à la collectivité ${ }^{53}$; à des sommes imputées à des individus et à des sommes récoltées ${ }^{54}$; à des

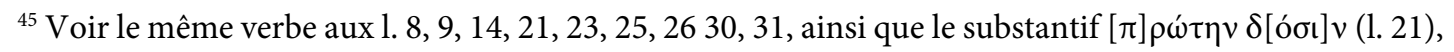

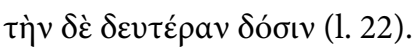

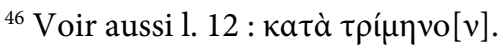

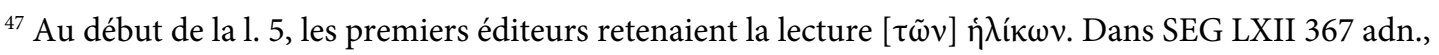

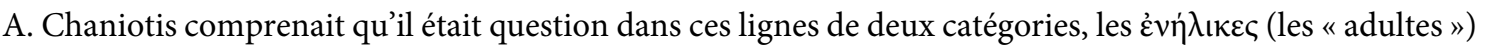
et les $\mu$ ì $\dot{v} \eta \dot{\lambda} \lambda \iota \kappa \varepsilon \varsigma$ (les « mineurs »).

${ }^{48}$ Pour des exemples de souscriptions publiques en vue du financement d'un service de protection du territoire et de ses ressources, voir Migeotte 1992, nos 16-17.

${ }^{49}$ Voir 1. 10, 13 15, 24.

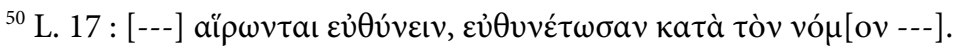

${ }^{51}$ Voir aussi 1. 16, 19, 29.

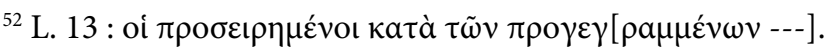

${ }^{53}$ L. 8 : [

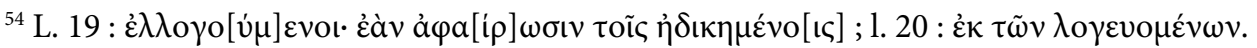


ventes ordonnées par les tagoi ${ }^{55}$; à des mesures intentées contre des individus " au nom de la cité selon la loi $»^{56}$. Ces contestations, et les transactions qui en résultent, pourraient avoir consisté en des litiges fonciers ou en des délits commis sur des propriétés se trouvant dans les campagnes, d'où la nécessité qu'aurait éprouvée la cité de Doliché de faire surveiller son territoire. En tout état de cause, la tâche de surveillance qui fut attribuée à Ménôn porta sur des secteurs précis du territoire, car les différentes zones à garder - qui, cumulées, couvrent la plus grande partie de la chôra de Doliché - sont soigneusement décrites (1.33-54), leurs limites étant identifiées à l'aide de points

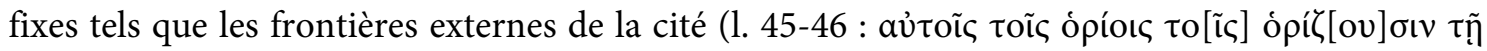

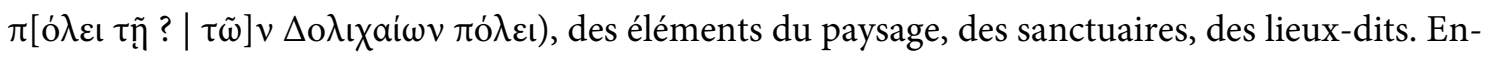
fin, il est question, aux 1. 52-53, de " destructions avec violence ${ }^{57}$, ce qui semble confirmer que la tâche de Ménôn était liée à des délits commis dans la chôra et à des atteintes portées contre des propriétés privées, et peut-être plus précisément contre leurs bornes de délimitation. La référence à un $\delta$ iá $\tau \alpha \gamma \mu \alpha$ à la 1.10 semble, en outre, renvoyer à une disposition prise par une entité extérieure à la cité de Doliché, sans doute en l'occurrence par les autorités romaines, ce terme désignant le plus souvent un édit émanant d'un représentant de ces dernières, en particulier d'un gouverneur ${ }^{58}$. De même que Paul-Émile, en qualité de proconsul, eut à intervenir en 167 a.C. dans la cité de Gonnoi pour faire respecter la redistribution de terres à laquelle les autorités romaines avaient

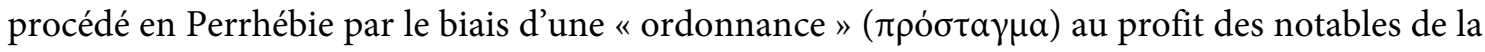
région s'étant montrés favorables aux intérêts de Rome à l'issue de la troisième guerre de Macédoine $^{59}$, on pourrait éventuellement concevoir que les troubles auxquels il est fait allusion dans l'inscription de Doliché aient été, ici aussi, les conséquences lointaines des remaniements fonciers provoqués par l'intervention de Rome en Thessalie. Mais si une datation plus tardive, au milieu du I ${ }^{\text {er }}$ s. a.C., devait en fin de compte être privilégiée pour l'inscription, il serait toutefois préférable - en raison du hiatus chronologique - de ne pas lier les deux événements et de considérer plutôt que l' « ordonnance » romaine, dont il n'est pas même certain qu'elle ait porté spécifiquement sur des questions liées à la gestion du territoire, fut prise à une autre occasion, qui demeure indéterminée.

Pour ce qui est de la mise sur pied de la surveillance territoriale, on pourrait concevoir que le tirage au sort par tribu civique (1. 7) n'ait pas eu pour objet de financer ce service, mais plutôt de fournir, parmi les citoyens dont il est question à la $1.4(\tau \tilde{\omega} v \pi 0 \lambda i ́ \tau \omega v)$, des hommes utiles à la

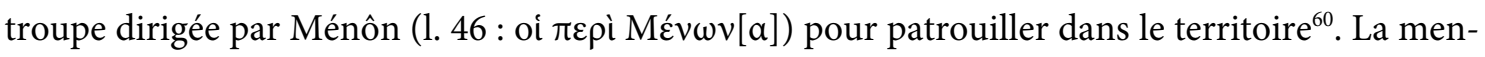
tion de différentes classes d'âge, qui fait penser aux structures des associations éphébiques et à

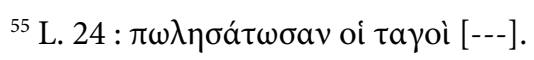

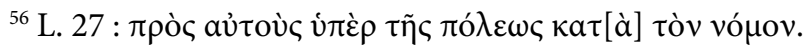

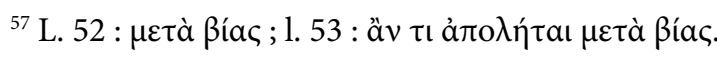

${ }^{58}$ Mason 1974, 126-127.

${ }^{59}$ Bouchon 2014.

${ }^{60}$ Dans la notice SEG LXII 367, A. Chaniotis, sur une suggestion de M. Hatzopoulos, édite à la 1.7

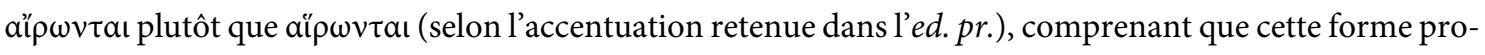
vient du verbe ảeí $\rho \omega / a i l \rho \omega$ (et non ai $\rho \varepsilon ́ \omega)$, qui se dit de la levée de troupes. Une telle interprétation rendrait toutefois délicate l'articulation entre le verbe conjugué AIP $\Omega$ NTAI et l'infinitif $\delta\llcorner\alpha \kappa \lambda \rho \omega ́ \sigma \alpha \sigma \theta a ı$ qui le suit immédiatement.
} 
une organisation de nature paramilitaire, semble aller dans le même sens ${ }^{61}$ : ces contingents seraient donc plutôt les bénéficiaires des versements ${ }^{62}$. En outre, il semble être question, aux 1. 30-

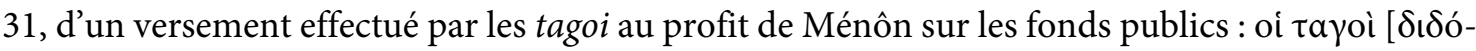

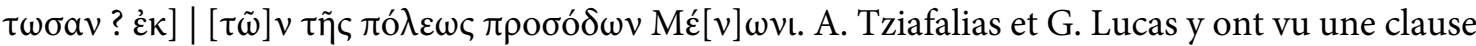
supplémentaire prévoyant qu'en cas de non-versement de sa rémunération à Ménôn en raison d'une défaillance des contributions des tribus, celui-ci se verrait néanmoins payer directement par les revenus de la cité. Une autre solution consisterait à voir dans ces revenus publics la source principale de la rétribution de Ménôn en personne, tandis que les multiples versements énumérés aux lignes précédentes et répondant à un échéancier précis concerneraient plutôt le paiement des hommes de sa troupe directement par les magistrats de la cité, sans qu'il soit question d'une souscription. La périodicité des versements et la référence au tirage au sort des tribus indiqueraient les modalités du service des patrouilleurs : ceux-ci pourraient avoir alterné dans leur fonction par cycles de trois mois et par roulement entre les tribus.

Quels qu'aient été les détails de l'organisation pratique de la paraphylakè et de sa gestion financière, qui nous échappent en raison de l'état désespéré de l'inscription ${ }^{63}$, on peut néanmoins établir que la surveillance du territoire à Doliché faisait l'objet d'un service attribué par la cité à un particulier - les obligations de l'une et l'autre partie étant énoncées contractuellement - et que ce service, au contraire des cas où la phylakè tès chôras était mise à ferme que nous avons examinés plus haut, était directement rémunéré par les fonds publics. Celui-ci impliquait, contre rétribution, la participation physique de groupes de citoyens pour patrouiller dans la chôra. L'établissement d'un service de paraphylakè à Doliché paraît avoir été étroitement lié à des litiges fonciers et la mission des patrouilleurs formant la troupe de Ménôn semble avoir consisté surtout à prévenir les accaparements de propriétés. Même s'il n'est pas assuré que Ménôn ait pu percevoir luimême des amendes, son action paraît avoir eu des implications financières non négligeables pour la cité (il est fait mention à plusieurs reprises d'un montant fixe de 650 tétradrachmes) ${ }^{64}$. Le cas de Doliché permet de rappeler que, dans les cités grecques à l'époque hellénistique, la surveillance de la chôra ne se limitait pas à la défense militaire du territoire ou à la lutte contre le brigandage et montre qu'on concevait que la sécurité de la cité passait aussi par la préservation des propriétés foncières appartenant aux particuliers, dont l'intégrité pouvait être protégée par l'organisation d'un service public de patrouilleurs.

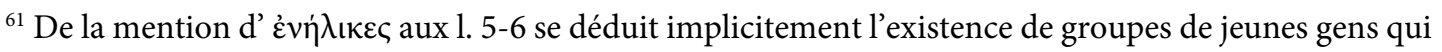
n'étaient pas encore adultes. Pour l'utilisation de cette terminologie dans le cadre des institutions éphébiques, voir Chankowski 2011, 69-71.

${ }^{62}$ C'était déjà l'interprétation retenue par M. Hatzopoulos et A. Chaniotis dans SEG LXII 367 adn.

${ }^{63}$ Ainsi, à la l. 2, dans une partie de l'inscription très lacunaire, B. Helly et R. Bouchon proposent de lire $[\tau \tilde{\eta} \varsigma] \dot{\eta} \mu<i>\sigma<\varepsilon>\omega \varsigma \tau \tilde{\eta} \varsigma \delta \varepsilon \kappa \alpha \dot{\tau}<\eta>\varsigma$. Le lien entre cette dîme et le financement du service de surveillance territoriale décrit plus bas demeure indéterminé. Pour les taxes dans les cités thessaliennes, voir supra pour l'existence d'une dîme à Krannon ainsi que Helly 2008.

${ }^{64}$ Voir 1. 18, 21, 29. Pour un autre exemple de montage financier complexe dans une cité thessalienne à l'époque hellénistique, voir Helly - Tziafalias 2013.
} 


\section{La fonction de paraphylaque dans les cités d'Asie Mineure à l'époque impériale : nature et finan- cement de la charge, compétences économiques}

L'avènement de la domination romaine en Méditerranée orientale à partir du début du $\mathrm{II}^{\mathrm{e}}$ s. a.C., puis la pacification qui fut imposée aux provinces balkaniques et anatoliennes sous le principat d'Auguste ne firent pas disparaître la nécessité que les cités grecques avaient de maintenir l'ordre public sur leur territoire. En plus des litiges fonciers entre particuliers, impliquant parfois également le domaine public, et des différends frontaliers entre cités, qui pouvaient donner lieu à des accès de violence ${ }^{65}$ et qui nécessitaient le plus souvent l'intervention et l'arbitrage des autorités romaines ${ }^{66}$, les actes de brigandage demeurèrent, avec une acuité variable suivant les régions, un phénomène endémique qui ne fut jamais entièrement éradiqué sous l'hégémonie de Rome ${ }^{67}$. Dans ces conditions, la surveillance du territoire, comme cela avait été le cas à l'époque hellénistique, continua à être une des compétences des cités grecques dans l'Empire romain pacifié. Paradoxalement, c'est à l'époque où les communautés locales avaient perdu définitivement leur indépendance en matière militaire ainsi que dans le domaine de la politique extérieure que les cités d'Asie Mineure se dotèrent d'institutions de police permanentes. En créant plusieurs charges publiques dévolues expressément à la sécurité publique sur leur territoire au cours du $\mathrm{I}^{\mathrm{er}}$ et du $\mathrm{II}^{\mathrm{e}}$ s. p.C., les cités investirent la marge d'autonomie qui leur était concédée sous le régime provincial romain, selon un partage des tâches empirique entre, d'une part, les autorités romaines qui - par le biais de l'armée - protégaient les frontières externes de l'Empire et n'intervenaient dans les provinces qu'en cas de danger persistant ou extraordinaire ${ }^{68}$ et, d'autre part, les communautés locales qui veillaient à l'ordre public au quotidien sur l'étendue de leur territoire. L'attention que les cités accordèrent à leurs institutions de police fut d'autant plus grande qu'elles avaient été entièrement désarmées depuis l'époque augustéenne. L'entretien de forces de police fut, pour certaines cités, l'occasion de raviver leurs traditions militaires désormais révolues, en donnant des atours guerriers aux opérations de maintien de l'ordre qu'elles effectuaient sur leur territoire ${ }^{69}$.

\subsection{Le financement de la charge de paraphylaque}

Une de ces charges de nature policière, spécialement affectée à la surveillance de la chôra, était la

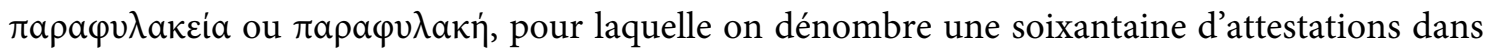
les cités d'Asie Mineure, principalement en Ionie, en Carie, en Phrygie et en Lycie ${ }^{70}$. Dans certaines cités, la fonction semble avoir été attribuée aussi régulièrement qu'une magistrature, comme à Éphèse, par exemple, où elle était pleinement intégrée dans la carrière locale, à un rang hiérarchique moindre toutefois par rapport aux fonctions les plus en vue, comme la magistrature

\footnotetext{
${ }^{65}$ Voir, par exemple, le contentieux territorial entre les cités de Tarse et de Mallos en Cilicie : Dion Chrysostome Or. 34 [Second Discours à Tarse]. 11,14,27.

${ }^{66}$ Burton 2000.

${ }^{67}$ Shaw 1984 ; Wolff 2003.

${ }^{68}$ Brélaz 2005, 231-320 ; Fuhrmann 2012.

${ }^{69}$ Brélaz 2008 ; Brélaz 2015.

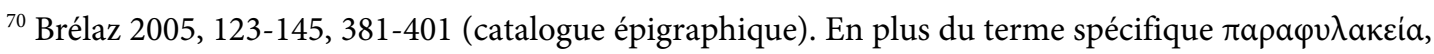

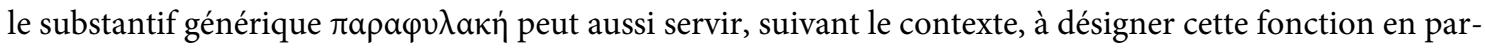
ticulier plutôt qu'une activité de surveillance au sens général.
} 
de secrétaire du peuple, qui était réservée à la frange supérieure de l'élite locale ${ }^{71}$. Pour notre propos se pose en particulier la question du financement des coûts induits par la mission confiée aux paraphylaques, en l'occurrence l'entretien de la petite troupe de gardes qui les accompagnaient lors de leurs tournées dans le territoire ${ }^{72}$. Deux inscriptions récemment publiées font allusion aux implications financières de la mise sur pied d'un service de surveillance territoriale par des paraphylaques.

En l'an 103 p.C., un certain Achaïkos fils d'Oxathrès, euposiarque et paraphylaque, fut ainsi honoré d'une stèle commémorative par les Trikkeanoi, les habitants d'une communauté rurale située sur le territoire de la cité de Nicée en Bithynie, qui motivèrent leur initiative de la façon suivante :

« en raison de son dévouement envers notre cité et de la fonction de paraphylaque de toute la Plassyènè qu'il veilla à prendre à sa charge et qu'il restaura l'année de sa propre magistrature (...), en hommage et pour son mérite $»^{73}$.

Plutôt que de désigner les Trikkeanoi eux-mêmes, le terme polis renvoie certainement ici à la cité de Nicée, car les fonctions d'euposiaque et de paraphylaque revêtues par Achaïkos le furent, selon toute vraisemblance, dans le cadre d'institutions civiques plutôt que de celles d'un village, aussi grand soit-il. En recourant de manière affective au possessif $\eta \mu \tilde{\omega} v$ et en évoquant ainsi « leur cité ", les Trikkeanoi affirmèrent, malgré leur éloignement du centre urbain, leur appartenance à la cité de Nicée et soulignèrent que les bienfaits dont s'était acquitté Achaïkos envers leur communauté avaient profité à l'ensemble de la cité, du moment que ce district en était une partie constitutive. En plus de confirmer l'ancrage territorial de la fonction de paraphylaque, dont la mission

\footnotetext{
${ }^{71}$ Kirbihler 2012.

${ }^{72}$ Ces gardes ne paraissent pas avoir porté de nom particulier : peut-être les qualifiait-on simplement de

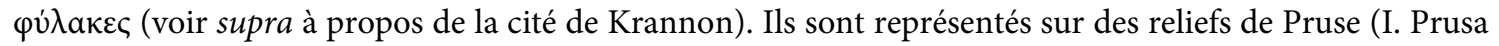
ad Olympum 23 : voir infra n. 88), du territoire d'Éphèse (Speidel 1985 avec pl. 1) et du territoire de Hiérapolis en Phrygie (communauté des Motaleis, à l'extrémité nord-est de la chôra hiérapolitaine : T. Ritti dans D’Andria et al. 2012, 697-699 no. 8 avec fig. 7, B ; cf. Ritti 2017, 73-74 avec fig. 13). L'identification de cinq membres de l'escorte d'un paraphylaque sur ce dernier relief (appartenant à un monument honorifique?), bien que celui-ci ne porte aucune inscription mentionnant ce titre, est rendue très probable, outre la mention à plusieurs reprises de paraphylaques dans des documents provenant de cette portion du territoire de Hiérapolis, par la ressemblance de leur équipement avec celui des gardes figurés sur le relief éphésien : ils sont vêtus d'une tunique courte, portent des lanières de cuir sur le ventre comme protection et sont armés de faisceaux de verges et de bâtons recourbés ou de massues. On peut comparer ces gardes aux diogmites secondant les irénarques ou aux mastigophores utilisés pour maintenir l'ordre lors de rassemblements de foule : voir Brélaz 2005, 145-157, 171-182 et infra n. 108. Ritti 2002, 44-47, propose de reconnaître pareillement des gardes territoriaux (en particulier des (h)orophylaques selon son interprétation) dans la figuration sur un sarcophage provenant des environs de Thiounta, toujours dans la même partie du territoire de Hiérapolis, de quatre hommes cuirassés, armés de lances et de bâtons et accompagnés pour certains de chiens et d'un cheval. D'autres reliefs provenant des environs de Hiérapolis représentent des gardes légèrement armés (lances, bâtons, cuirasses, petits boucliers, chiens) : Ritti et al. 2008, nos 97-104. On peut leur comparer l'équipement de gardiens de domaines privés : voir Brélaz 2005, 166-167 avec n. 429.

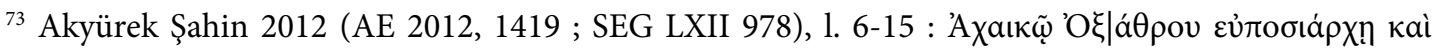

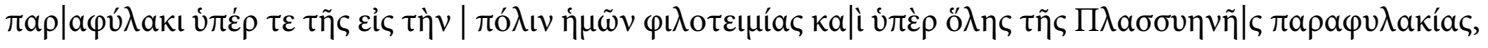

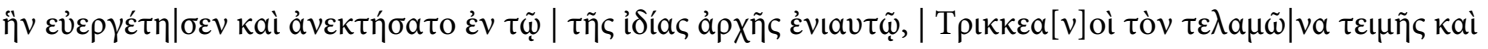

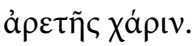


semble avoir été limitée, dans le cas présent, à une portion circonscrite de la chôra de Nicée (en l’occurrence la région appelée Plassyènè, située au sud du centre urbain $)^{74}$, cette inscription montre que le service de surveillance territoriale avait été financé par le magistrat. Il semble, en

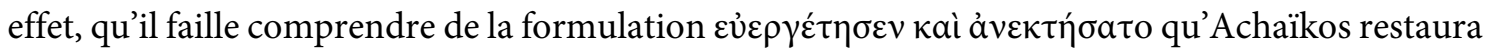
la charge de paraphylaque, qui pouvait être tombée en désuétude et qui n'avait peut-être plus été exercée dans l'ensemble du district en question les années précédentes, en couvrant les frais nécessaires à son rétablissement ${ }^{75}$. Le lexique de l'évergétisme ici utilisé suggère une dépense personnelle ${ }^{76}$. On relèvera que la charge d'euposiarque, qui fut revêtue par le même magistrat et qui consistait en l'organisation du ravitaillement de la cité, supposait aussi ordinairement d'y consacrer des ressources propres de la part de ses titulaires ${ }^{77}$.

La seconde inscription fut érigée dans le courant du II ${ }^{\mathrm{e}}$ s. p.C. par la communauté rurale de Thiounta, située sur le territoire de la cité de Hiérapolis en Phrygie, en l'honneur d'un certain Théotimos - le descendant d'une lignée d'évergètes de la cité commémorés par la même occasion - qui s'acquitta de diverses magistratures et liturgies (stratégie à deux reprises, agoranomie, sitôneia) : parmi elles, on relève « la charge de paraphylaque qu'il accomplit avec intégrité et de manière avantageuse, avec force dépenses $»^{78}$. Dans ce cas aussi, l'expression utilisée indique que l'exercice de la charge de paraphylaque pouvait entraîner des frais pour celui qui s'en acquittait. Le fait que ces deux paraphylaques, Achaïkos à Nicée et Théotimos à Hiérapolis, aient contribué sur leurs fonds privés à l'entretien du service dont ils avaient la charge n'implique pas, toutefois, qu'aucun budget n'ait été mis à disposition en temps normal pour l'accomplissement de cette tâche et que la fonction de paraphylaque doive être considérée comme une liturgie. Comme nous l'avons relevé ci-dessus à propos de la cité d'Éphèse et comme le confirme l'inscription de Nicée où celle-ci est explicitement qualifiée d'ả $\rho \chi \eta ่$, la charge de paraphylaque figurait parmi les magistratures civiques. La distinction entre magistratures et liturgies était néanmoins devenue extrêmement ténue dans les cités grecques à l'époque impériale et, dans le contexte de la compétition qui animait les notables pour s'acquitter de charges d'intérêt public, il était habituel que les magistrats fassent preuve d'évergétisme dans l'exercice de leurs fonctions et sacrifient une partie de leur fortune personnelle à l'entretien du service dont ils avaient la responsabilité (quoique cela n'ait pas pris un tour aussi systématique et formalisé que la summa honoraria qui était exigée des détenteurs des charges publiques dans les municipes et colonies romains) ${ }^{79}$.

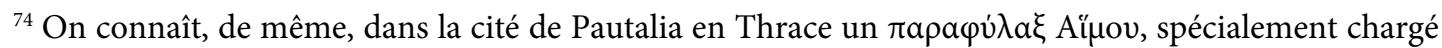
de la surveillance territoriale dans le massif de l'Haemos (IGBulg IV 2147). On ne saurait y voir une fonction militaire romaine, comme le fait Moreau 2010, 69-71.

${ }^{75}$ Comparer le verbe ả $\pi[0] \kappa a \tau \alpha \sigma \tau \eta ́ \sigma \omega \sigma \iota v$ apparaissant dans l'inscription de Doliché commentée cidessus (SEG LXII 367, 1. 8 : voir supra n. 53) et se référant éventuellement aussi au rétablissement d'une fonction liée à la surveillance du territoire.

${ }^{76}$ Pour un autre paraphylaque qui fut qualifié d' " évergète " par des bergers sur le territoire de Nicée, voir infra n. 90.

77 Voir le commentaire d'A. Avram à I.Callatis 32.

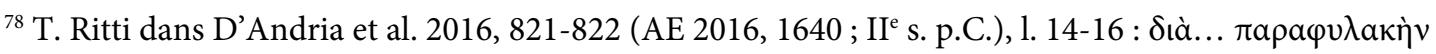

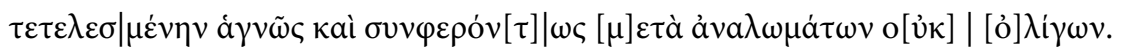

${ }^{79}$ Kleijwegt 1994 ; Dmitriev 2005, 152-157.
} 
L'ambiguité relative au statut et au financement des fonctions publiques à l'époque impériale est illustrée par une autre charge de police répandue dans les provinces anatoliennes, voisine de la magistrature de paraphylaque et assumée parfois par les mêmes personnages au cours de leur carrière civique : l'irénarchie. Bien qu'elle ait été revêtue aussi régulièrement que la charge de paraphylaque dans une quantité de cités, dont Éphèse, et quoiqu'elle y ait présenté toutes les caractéristiques ordinaires d'une magistrature, l'irénarchie fut, pour sa part, enregistrée au nombre des munera personalia par les juristes romains au cours de l'époque impériale avancée, aux côtés de fonctions intéressant en particulier le ravitaillement des communautés locales ou la collecte des impôts ainsi que d'autres charges de police, comme les fonctions de liménarque, de stratège de nuit et de mastigophore ${ }^{80}$. Les paraphylaques, pour leur part, n'apparaissent pas dans cette énumération, qui, par ailleurs, n'avait pas vocation à être exhaustive. À la différence des paraphylaques, les irénarques étaients les interlocuteurs privilégiés des autorités provinciales en raison de leur collaboration dans le cadre de la procédure pénale : de par les opérations de police qu'ils assuraient localement et leur spécialisation dans la répression des délits, les irénarques étaient, en effet, chargés, en cas d'arrestation, de mener une enquête préliminaire et de déférer devant le tribunal du gouverneur les prévenus susceptibles de tomber sous sa juridiction, en particulier en cas d'homicide, de troubles graves de l'ordre public ou de subversion. De ce fait, les irénarques se révélaient indispensables aux gouverneurs pour mener à bien les missions de maintien de l'ordre qui leur avaient été confiées par l'empereur dans les limites de leur province ${ }^{81}$. L'importance du travail des irénarques pour les autorités romaines était telle qu'empereurs et gouverneurs légiférèrent à plusieurs reprises pour encadrer leurs compétences et limiter leurs abus; les proconsuls participèrent même, du moins dans la province d'Asie dans le courant du $\mathrm{II}^{\mathrm{e}} \mathrm{s}$., au processus de sélection des candidats avant leur nomination par les différentes cités ${ }^{82}$. Le profit que les autorités romaines tiraient de la charge d'irénarque pourrait expliquer que celle-ci ait été classée parmi les munera plutôt que parmi les honores ${ }^{83}$. La qualification de l'irénarchie en tant que munus signifiait qu'à l'inverse d'une magistrature, pour laquelle on sollicitait en principe des candidatures volontaires et on procédait à une élection, celle-ci pouvait être imposée à un individu par les conseils municipaux. Les cités étaient ainsi assurées de ne jamais manquer de titulaires. Même si, dans les faits, la fonction d'irénarque était, dans de nombreuses cités d'Asie Mineure, attribuée annuellement comme on l'aurait fait pour n'importe quelle magistrature et qu'elle était intégrée dans la carrière civique locale, le fait qu'elle ait été considérée, techniquement parlant, comme une charge de contrainte, ou une liturgie, avait des conséquences sur les procédures de recours qu'il était possible d'engager devant les autorités provinciales en cas de contestation d'une nomination. En l'occurrence, l'irénarchie fut caractérisée comme munus personale, par opposition aux munera patrimonii, signifiant par là qu'au contraire des charges qui exigeaient de leurs titulaires une contribution financière grevant leurs propres ressources - telles que celles en lien avec la collecte des impôts, comme la fonction de dékaprôtos dont il sera question plus bas -, l'irénarchie consistait avant tout en une charge d'intendance d'un service d'intérêt public, dans ce cas la disponibilité à

${ }^{80}$ Char. (sing. de mun. civ.) Dig. 50.4.18. Voir Brélaz 2005, 90-122. Pour ces autres charges de police, voir Brélaz 2005, 72-74, 79-84, 171-182.

${ }^{81}$ Fournier 2010, 276-294; Jördens 2011.

${ }^{82}$ Brélaz 2011 : pour l'établissement du texte de l'inscription d'Acmonia qui fait l'objet de cette étude, voir Blanco-Pérez 2013 (AE 2013, 1528).

${ }^{83}$ Cf. Pont 2017, 37-38 n. 12. 
gérer un service de maintien de l'ordre, laquelle ne supposait pas de payer ou d'avancer des sommes d'argent ${ }^{84}$. Cela n'interdisait toutefois pas aux irénarques de s'acquitter d'évergésies dans l'exercice de leurs fonctions. Cela pouvait passer, par exemple, par la prise en charge de la troupe de gendarmes (appelés diogmites) qui les secondaient ${ }^{85}$.

\subsection{Aspects économiques de la présence et de l'action des paraphylaques dans les campagnes : évergé- sies, contrôle et exactions}

Plusieurs documents illustrent les activités des paraphylaques dans leurs compétences de surveillance territoriale et les mettent en scène effectuant des tournées dans la chôra. Un bâtiment utile au culte de la Mère des dieux des Montagnes fut ainsi érigé et dédié par un paraphylaque à la faveur de l'une de ses patrouilles sur le territoire de la cité d'Apollonia de la Salbakè en Carie ${ }^{86}$. Le paraphylaque fut accompagné, pour l'occasion, par une petite troupe de dix jeunes gens (veavíoкoเ) montés, de leur chef, le néaniscarque, et de quelques palefreniers et assistants. Ces jeunes gens

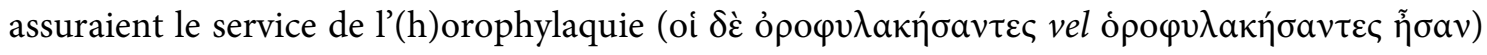
dont il a été question plus haut à propos de la défense du territoire dans certaines cités à l'époque hellénistique et qui consistait à patrouiller aux confins de la chôra. La participation de ces jeunes gens à la tournée du magistrat - lesquels furent également mis à contribution pour la construction du bâtiment - suggère que les paraphylaques pouvaient périodiquement s'adjoindre le concours des membres des associations éphébiques pour les besoins de leur mission ${ }^{87}$.

Les tournées des paraphylaques dans les campagnes les mettaient en relation directe avec les communautés rurales, avec lequelles ils entretenaient des relations privilégiées. Les habitants d'un village situé sur le territoire de la cité de Pruse en Bithynie érigèrent ainsi une stèle - ornée d'un relief représentant l'intéressé accompagné de sa suite - en l'honneur d'un paraphylaque «qui [avait] veillé sur eux à de nombreuses reprises et qui [s'était] montré irréprochable et serviable »

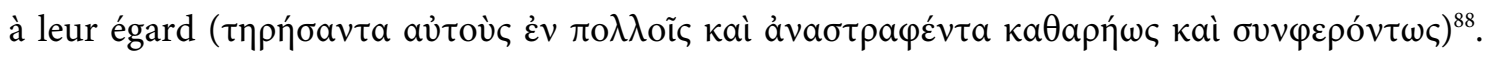
Toujours en Bithynie, nous avons déjà mentionné ci-dessus la reconnaissance que les Trikkeanoi,

\footnotetext{
${ }^{84}$ Horstkotte 1996 ; Drecoll 1997.

${ }^{85}$ Un magistrat de la cité d'Aizanoi en Phrygie, certainement en qualité d'irénarque, fournit ainsi à ses frais un diogmite à l'empereur Marc Aurèle en prévision de ses campagnes germaniques (OGIS 511 ; IGR

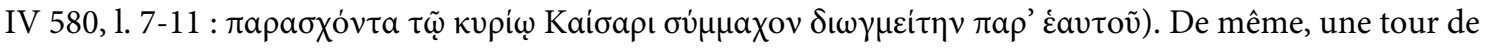
fortification fut inaugurée par un irénarque sur le territoire de Termessos, sans toutefois que soit précisée l'origine des fonds (TAM III 941).

${ }^{86}$ Robert, Carie, 281-283 no. 162 avec pl. XLV (seconde moitié du II ${ }^{\mathrm{e}}$ ou début du III ${ }^{\mathrm{e}}$ s. p.C.). Voir, de même, les dédicaces que des irénarques accompagnés de leurs diogmites ont gravées sur les parois d'une grotte de Pisidie située aux confins des territoires des cités de Sia et d'Ariassos : Brélaz 2005, 373-374 no. B 85 ; ce lot d'inscriptions a fait l'objet d'une récente réédition : SEG LXV 1316-1332.

${ }^{87}$ Brélaz 2005, 190-193. On a connaissance à Héraclée du Pont d'un paraphylaque qui fut aussi éphébarque au cours de sa carrière (Öztürk 2016 ; III ${ }^{\mathrm{e}}$ s. p.C.) : ces deux fonctions sont cependant distinctes et leur mention conjointe, bien que les deux charges soient liées par la conjonction kaì dans l'énumération de la carrière de l'intéressé, ne saurait prouver qu'ait existé un lien direct entre les deux institutions. Le relief décorant la stèle funéraire représente un homme dressant un bâton en direction de deux lutteurs : il s'agit certainement du défunt lui-même dans l'exercice de ses fonctions d'éphébarque, arbitrant un combat au gymnase.
}

${ }^{88}$ I. Prusa ad Olympum 23 (milieu du II ${ }^{\text {e }}$ s. p.C. : cf. Leschhorn 1993, 191). 
sur le territoire de la cité de Nicée, avait témoignée envers un paraphylaque pour avoir réorganisé le service de surveillance dans la portion de la chôra où ils étaient établis ${ }^{89}$. À un autre point du territoire de Nicée, des bergers honorèrent, de même, un certain P. Aelios S[---] qui avait été " leur bienfaiteur durant toute la durée de sa charge de paraphylaque, un homme juste et de valeur, qui [avait] exercé avec intégrité et de façon incomparable ses fonctions de paraphylaque » : cet élan de reconnaissance fut sans doute motivé par la sécurité dont les bergers et leurs troupeaux avaient pu bénéficier grâce aux patrouilles du magistrat ${ }^{90}$. Les paraphylaques étaient certainement les principales autorités civiques auxquelles étaient confrontés les habitants des campagnes et ces magistrats exerçaient, de fait, un ascendant sur les villageois. À Colophon, par exemple, les paraphylaques profitaient de leurs tournées pour célébrer la sécurité qu'ils apportaient à la cité et à son territoire par des distributions gratuites de vin, tant en ville que dans les campagnes. Ces actes d'évergétisme, auxquels ces magistrats n'étaient pas tenus et qui n'étaient pas directement liés à leur fonction, étaient néanmoins devenus à ce point fréquents au milieu du $\mathrm{II}^{\mathrm{e}} \mathrm{s}$. p.C. que les paraphylaques ou plutôt - semble-t-il - l'unique paraphylaque en fonction chaque année à Colophon semble s'en être acquitté régulièrement, peut-être à sa sortie de charge : une liste officielle datée par les prytanes éponymes de la cité et énumérant les noms des différents paraphylaques ayant offert ces largesses fut ainsi affichée sur une stèle dans le sanctuaire de Claros, indiquant que chacun d'eux (un seul étant mentionné par année), « ayant exercé la fonction de paraphylaque

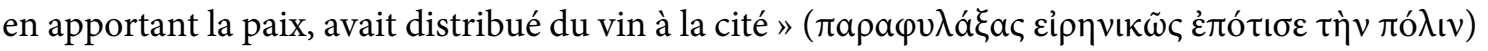
ou « avait exercé la fonction de paraphylaque et avait distribué du vin à la ville et aux campagnes,

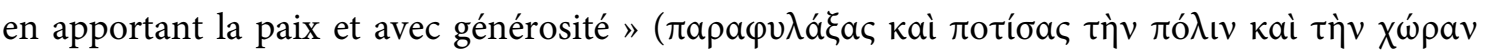

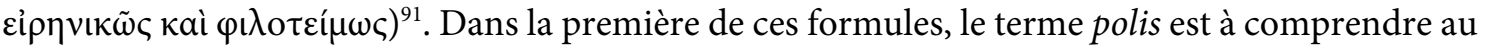
sens de cité en général, ce qui inclut également la population des campagnes, tandis que, dans la seconde où il est opposé à chôra, il désigne plus précisément la population urbaine par rapport aux habitants du territoire afin de signifier que l'ensemble des citoyens, quel qu'ait été leur lieu de résidence, bénéficièrent des distributions des paraphylaques. Enfin, à Chalkètôr en Carie, sur le territoire de la cité d'Iasos, fut commémorée l'activité d'un paraphylaque durant l'exercice de ses

\footnotetext{
${ }^{89}$ Voir supra n. 73.

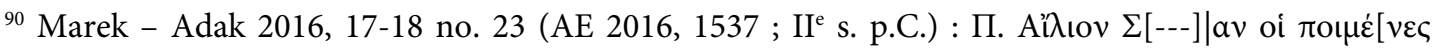

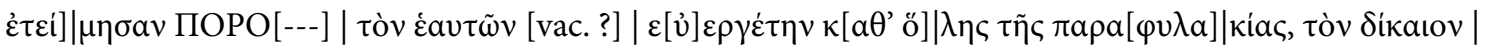

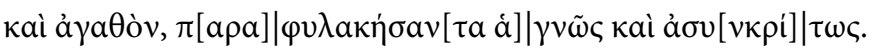

${ }^{91}$ Macridy 1905, 172-173 no. 7. La chronologie des prytanes éponymes de Colophon a pu être établie par Ferrary 2014, 74-82. Les bienfaits des paraphylaques ici célébrés concernent les années 146/7, 150/1, 162/3 ainsi que vraisemblablement 163/4 p.C. (ibid., 85 n. 21). Le fait que, dans cette liste, les années ne se suivent pas toutes n'implique pas que les bienfaits des paraphylaques n'aient été qu'épisodiques, car on ignore la forme du support originel sur lequel celle-ci était gravée : les informations concernant les autres années ici manquantes auraient pu être gravées sur d'autres plaques. Le fragment publié par Macridy 1912, 60 no. B, qui concerne l'année 164/5 ou 165/6 p.C., doit probablement ainsi être rapproché de la même

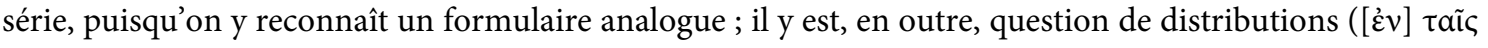

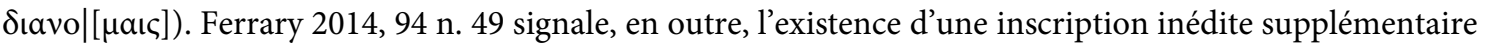
mentionnant un paraphylaque sur le modèle de la liste décrite ci-dessus.
} 
fonctions, dont le nom fut gravé sur une colonne aux côtés de la mention du stéphanéphore éponyme cette année-là (en l'occurrence l'empereur Trajan) et dont on veilla à préciser dans son titre

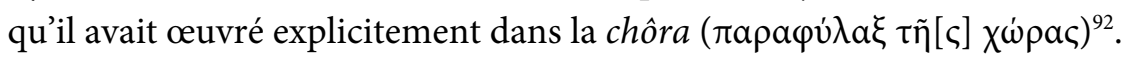

En dépit de ces témoignages qui attestent les bonnes relations entretenues entre les paraphylaques et les populations rurales, la présence dans les campagnes de ces magistrats et de leur troupe armée pouvait, paradoxalement, se révéler parfois menaçante pour les habitants de la chôra ${ }^{93}$. C'est ce que l'on déduit des motifs qui furent invoqués dans une série d'inscriptions honorifiques érigées dans le courant du I ${ }^{\text {er }}$ s. p.C. au profit d'un même paraphylaque par une communauté rurale du territoire de la cité de Hiérapolis dans le sanctuaire d'Apollon Karios, situé à une dizaine de kilomètres au nord-est du centre urbain ${ }^{94}$. Il y est dit du magistrat que celui-ci « s'acquitta de la fonc-

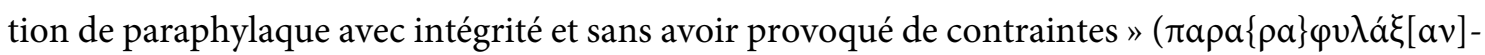

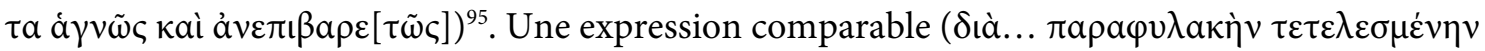
$\dot{\alpha} \gamma v \tilde{\omega} \varsigma$ kaì $\sigma v v \varphi \varepsilon \rho o ́ v \tau \omega \varsigma$ ) se trouve dans l'inscription qui fut érigée en l'honneur du paraphylaque Théotimos par la communauté de Thiounta, située à une vingtaine de kilomètres au nord de Hiérapolis et surplombant la vallée du Méandre, que nous avons déjà mentionnée plus haut ${ }^{96}$. La justification exprimée par ces villageois pour leur reconnaissance laisse entendre qu'un tel comportement de la part des paraphylaques n'allait pas nécessairement de soi. À l'instar des soldats romains et agents impériaux traversant les provinces pour les besoins de leurs missions, il arrivait

${ }^{92}$ Boulay - Pont 2014, 24-25 (AE 2014, 1312 ; SEG LXIV 935 ; 97-102 p.C.). La précision selon laquelle un paraphylaque a exercé dans la chôra se rencontre également à Éphèse (I.Ephesos 838) - où est aussi

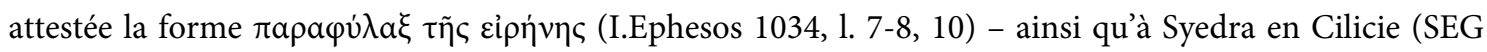
XLVIII 1797 ; AE 1998, 1420).

${ }^{93}$ Voir déjà, dans ce sens, Mitchell 1993, 195-197 dont le jugement doit toutefois être tempéré au vu de ce qui précède.

${ }^{94}$ T. Ritti dans D’Andria et al. 2012, 718-722, nos 8-10 (SEG LXII 1188-1191 ; Ier s. p.C.). Sur les rapports entre ces différentes inscriptions, voir infra n. 102.

${ }^{95}$ SEG LXII 1189, 1. 7-8. Pour le sens du qualificatif áyvó magistrats et fonctionnaires romains et soulignant leur intégrité morale et leur honnêteté, voir Heller -

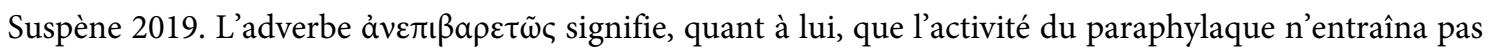
de charges supplémentaires pour la communauté. Voir, de la même manière, la cité d'Ilion (I.Ilion 102) qui a honoré un fonctionnaire romain, administrateur des biens fonciers de Drusus le Jeune, peut-être en Chersonèse de Thrace, pour avoir « anéanti les bandes de pirates dans l'Hellespont et préservé la cité intacte en

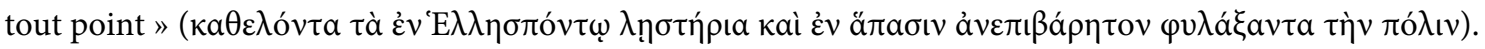

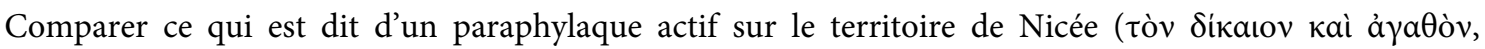
$\pi[\alpha \rho \alpha] \varphi v \lambda \alpha \kappa \eta \dot{\sigma \alpha} \alpha[\tau \alpha \dot{\alpha}] \gamma \nu \tilde{\omega} \varsigma \kappa \alpha i ̀ ~ a ̉ \sigma v[v \kappa \rho i ́] \tau \omega \varsigma)$ : voir supra n. 90.

${ }^{96}$ Voir supra n. 78. Le relief représentant probablement l'escorte d'un paraphylaque provenant aussi du nord de la chôra hiérapolitaine pouvait également appartenir à un monument honorifique : voir supra n. 72. Un paraphylaque apparaît à Thiounta comme membre d'une confrérie religieuse ayant organisé une fête nocturne en l'honneur de Zeus : Ramsay 1895, I, 143-144 no. 31 ; Ramsay 1927, 197 fig. 2 ; 201-211. Contrairement à l'opinion de Robert 1983b, 59-62, qui considérait que ce magistrat avait été expressément envoyé par la cité de Hiérapolis pour assurer l’ordre public lors de la fête, on peut concevoir que celui-ci ait agi ici à titre privé : cf. Schuler 1998, 277 avec n. 22. Le titre $\pi \alpha \rho \alpha \varphi \dot{\lambda} \alpha \xi$ pourrait aussi éventuellement plutôt désigner, dans ce contexte, un simple garde, reponsable de la bonne discipline lors des fêtes organisées par la confrérie. 
que les magistrats civiques se montrent coupables de rudoyer les populations rurales, en particulier en exigeant d'elles des contributions indues ${ }^{97}$. C'est précisément pour prévenir ce genre d'abus que la cité de Hiérapolis passa dans le courant du II ${ }^{\mathrm{e}}$ s. p.C. un décret visant à limiter au strict nécessaire les réquisitions auxquelles les paraphylaques pouvaient légalement procéder pour leur entretien lors de leurs séjours dans les villages :

«... Sous la stratégie de Théophilos, deuxième du nom, le Jeune, le dixième mois... Il a plu au conseil des Hiérapolitains, lors de la séance des élections. Qu’à l'avenir les paraphylaques fassent séjour à leurs frais dans les villages, à cette condition que (les villageois) ne fourniront à ceux-ci rien d'autre que du bois, du fourrage et un logement, et rien d'autre à personne d'autre de quelque façon que ce soit. Pour le cas où quelqu'un agirait contre ces dispositions ou serait complice d'une autre personne qui agirait ainsi, que celui qui aura été convaincu de l'avoir fait paie à titre d'amende à la caisse publique tout ce qu'on pourra l'accuser d'avoir reçu de quelqu'un et qu'il soit déchu des honneurs. De plus, que les paraphylaques incriminés ne reçoivent pas les (honneurs du village ?)... et que les chefs de villages ( $\kappa \omega \mu \alpha \dot{\rho} \chi \alpha \varsigma)$ ne couronnent pas un paraphylaque contre leur gré, mais que celui-ci restitue l'argent; si toutefois un village décidait de couronner un paraphylaque... que rien ne soit perpétré contre ces dispositions. Sinon, que celui qui contreviendra à ces mesures ne consacre pas d'offrande au sanctuaire d'Apollon. Ce décret fait autorité et est contraignant ${ }^{98}$.

Une copie de ce décret fut découverte au nord de Hiérapolis, en remploi dans le village de Çindere. Selon l'inventeur de l'inscription, J. G. C. Anderson, celle-ci provenait cependant à l'origine d'un village situé à env. 6 kilomètres au sud-ouest de l'emplacement du site antique de Thiounta ${ }^{99}$ : il s'agit certainement du village de Boyalli, qui abrite, lui aussi, un site antique. C'est dans cette dernière communauté rurale, qui eut probablement à pâtir des agissements des paraphylaques, comme les autres villages composant la chôra hiérapolitaine, que la copie dut être affichée ${ }^{100}$. Il est intéressant de relever que le décret n'envisage pas uniquement les exactions qui pouvaient être commises par les paraphylaques au cours de leurs patrouilles dans les campagnes, mais également les formes de racket que ceux-ci pouvaient exercer à l'encontre des populations rurales sous le couvert d'honneurs votés en leur faveur. Au-delà des marques de gratitude exprimées officiellement par certains villages envers les paraphylaques, il arrivait donc que la réalité des rapports

\footnotetext{
${ }^{97}$ Hauken 1998, 145-149, 1.19 (village d'Aragua près de la cité d'Appia en Phrygie, 244-246 p.C. : men-

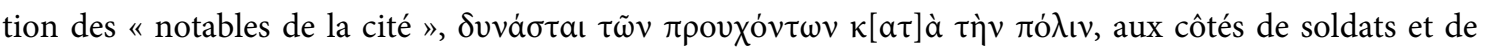
fonctionnaires impériaux, parmi les auteurs de méfaits); Marcian. (2 de iud. publ.), Dig. 48.3 .6 (arrestations abusives dues à des irénarques). Voir Brélaz 2011 ; Brélaz 2021b ; Uzunoğlu 2021.

${ }^{98}$ OGIS 527. Pour l'établissement du texte, voir Brélaz 2005, 394-396 no. C 51 et les quelques gains minimes à tirer de la récente réédition de l’inscription : voir infra n. 100.

${ }^{99}$ Anderson 1897, 411-413 no. 14.

${ }^{100}$ G. Scardozzi - M. Nocita dans D’Andria et al. 2016, 841-846 (avec reproduction et réédition de l'inscription OGIS 527 à la suite de sa redécouverte ; les 1. 1-3 sont désormais perdues, en plus de quelques lettres sur les marges gauche et droite). On ne peut tirer argument du fait que le décret fut pris à l'occasion de la séance des élections ( $\dot{\varepsilon} \pi \grave{\imath} \tau \tilde{\omega} v$ ả $\rho \chi \alpha[\imath] \rho \varepsilon \sigma \iota \tilde{\omega} v$ ) pour prouver que les paraphylaques étaient eux-mêmes élus par l'ekklèsia plutôt que par la boulè, comme le fait Fernoux 2011, 263-264.
} 
entre les habitants des campagnes et ces magistrats de police ait été plus rude que ne le laisse entendre la phraséologie irénique des inscriptions honorifiques.

À ce propos, il vaut la peine de revenir un instant aux inscriptions qui furent érigées dans le sanctuaire d'Apollon Karios, au nord-est de Hiérapolis. L'une des inscriptions en l'honneur du paraphylaque précise, en l'occurrence, que son frère, qui fut honoré par la même occasion, "fit preuve en toute chose des mêmes dispositions que son frère pour le mieux " (

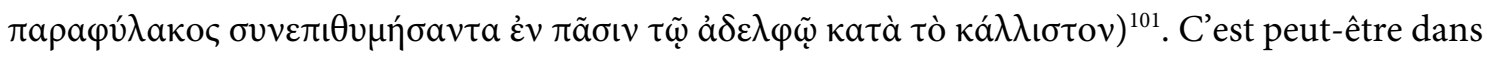
l'exercice de ses fonctions en tant que stratège de la cité que le frère du paraphylaque eut l'occasion de collaborer avec lui, car une deuxième inscription loue les deux frères en parallèle, l'un pour avoir été paraphylaque sans porter préjudice aux habitants du territoire - comme nous l'avons relevé plus haut -, l'autre pour « avoir revêtu la fonction de stratège de façon ferme ( ?) et juste »

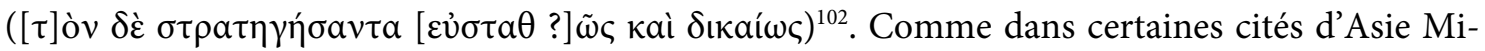
neure, l'ancienne magistrature militaire de stratège pouvait avoir conservé, à Hiérapolis, des compétences de maintien de l'ordre au cours de l'époque impériale et c'est donc leurs prérogatives policières respectives qui auraient pu être l'occasion de la collaboration entre les deux frères, le paraphylaque s'attachant le concours de son frère stratège ${ }^{103}$. Cette association de deux frères dans l'exercice de la surveillance du territoire fait songer à ce que nous avons dit plus haut de Deinias dans la cité thessalienne de Krannon au IV ${ }^{e}$ s. a.C. À la différence toutefois des deux frères de Hiérapolis dont le comportement fut manifestement exemplaire, du moins tel que le présentent les villageois, Deinias s'était assuré le concours de son frère pour rançonner les populations des campagnes à l'occasion de la levée des impôts.

En dehors des contributions supplémentaires dont les paraphylaques pouvaient épisodiquement grever les communautés rurales du fait de leurs excès, ceux-ci, en tant que principaux magistrats civiques actifs dans la chôra, étaient, en temps normal, amenés à exercer une supervision sur les activités économiques qui se déroulaient dans les campagnes. On a ainsi connaissance, toujours à Hiérapolis, de la copie épigraphique d'un document officiel, trouvé à Develler aux confins nordest du territoire de la cité et daté du milieu du III s. p.C., introduisant des mesures de protection contre les dommages causés aux vignobles, en particulier par le bétail. Parmi les quelques clauses

${ }^{101}$ SEG LXII 1188, 1. 7-9. La nuance que comporte le verbe $\sigma v v \varepsilon \pi \imath \theta u \mu \dot{\omega} \omega$ est malaisée à saisir : si T. Ritti dans D'Andria et al. 2012, 718-722 nos 8-10, par sa traduction, place les deux frères sur un pied d'égalité ( « in tutto si è adoperato a collaborare con il fratello »), P. Hamon, BE 2014, 464, préfère introduire une idée de subordination du frère au paraphylaque : « [il] s'est conformé en toute chose aux souhaits de son frère ».

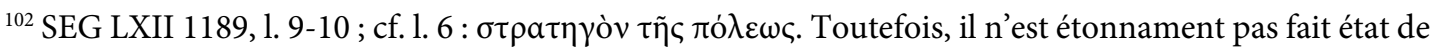
la qualité de stratège du frère du paraphylaque dans l'inscription SEG LXII 1188, qui pourrait donc lui être de peu antérieure. Pour sa part, P. Hamon, BE 2014, 464 met en doute l'identification des mêmes frères dans ces deux inscriptions. Le frère du même paraphylaque fut cependant aussi honoré dans une troisième inscription dont le texte n'a pas pu être copié par l'éditrice (SEG LXII 1190). Enfin, la même expression que dans SEG LXII 1189, 1. 7-8 doit peut-être être restituée dans une quatrième inscription très fragmentaire (SEG LXII 1191) où il est question d'offrandes et de relations avec les populations environnantes (1. 7-9 :

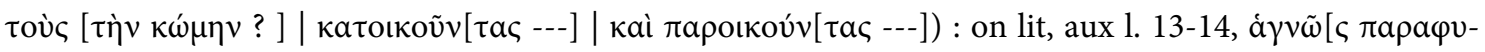

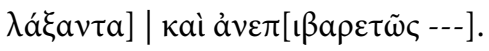

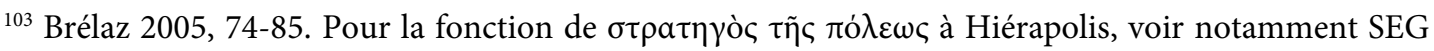
XLVII 1729 (époque flavienne). 
conservées, il est fait référence, à propos des individus responsables d'avoir endommagé les plantations, aux compétences des paraphylaques :

«que les bergers - si ce sont des esclaves qui ont été dénoncés aux paraphylaques nommés pour l'année - soient fouettés pour les dissuader de persévérer dans leur injustice ; quant aux propriétaires des troupeaux, aux bergers de condition libre et aux surveillants des terrains qui n'ont pas empêché les bergers de conduire leurs troupeaux dans les vignes et d'arracher des ceps dans celles-ci, il est autorisé de leur saisir d'autres de leurs biens à titre de compensation ainsi que de leur prendre un gage... $»^{104}$.

Les éditeurs du quatrième tome des Monumenta Asiae Minoris Antiqua, suivis par D. Magie, interprétaient ce document comme un édit du proconsul d'Asie et restituaient, par conséquent, le verbe $\kappa \varepsilon \lambda \varepsilon v \dot{\omega} \omega$ à la fin de la 1.8 pour introduire la clause que nous venons de citer ${ }^{105}$. La récente publication d'une nouvelle copie du même document, découverte en remploi dans le village de Dağmarmara correspondant à l'établissement antique de la communauté rurale des Motaleis, quelques kilomètres seulement à l'est de Thiounta, suggère plutôt d'y reconnaître un décret émanant de la cité de Hiérapolis qui fut affiché dans les différents villages constituant sa chôra ${ }^{106}$. Du reste, le caractère exclusivement municipal du document est rendu manifeste par la mention des magistrats civiques que sont les paraphylaques et les « surveillants des terrains » ( $\dot{\varepsilon} \pi \mu \varepsilon \lambda \eta \tau \alpha i ̀ ~ \tau \tilde{\omega} v$ $\chi \omega{ }^{\prime}(\omega v)$ ainsi que, plus loin dans le même document, d'Apollon Archégétès, la divinité principale de Hiérapolis ${ }^{107}$. On restituera donc plutôt à la fin de la 1.8 la tournure $\dot{\varepsilon} \xi \tilde{i} v a / / \dot{\varepsilon} \xi \tilde{v} v \varepsilon$ qui apparaît déjà à la 1. 11/2 (aussi restitué aux 1.1 et 3 ) de l'inscription de Develler et qui est également mentionnée dans une clause supplémentaire figurant dans la nouvelle copie provenant de Thiounta. Celle-ci introduit les dispositions prévues par la cité de Hiérapolis pour punir les contrevenants. On constate que les paraphylaques, s'ils ne sont pas directement sollicités pour éloigner des vignobles les voleurs ou les bergers négligents, jouent néanmoins un rôle dans l'enregistrement des

${ }^{104}$ MAMA IV 297 (vers 250 p.C.), 1. 8-17 ; cf. Thonemann 2011, 193-195 (sans texte grec). L'établissement du texte peut être révisé grâce à la nouvelle copie mentionnée infra n. 107. Sur l'appartenance de cette région à la cité de Hiérapolis, plutôt que de Dionysopolis comme le pensaient les premiers éditeurs, voir Robert 1962, 356-357 n. 5 ; G. Scardozzi dans D’Andria et al. 2016, 837-839.

105 Magie 1950, I, 647.

${ }^{106}$ Ritti et al. 2008, 68-72 avec fig. 15 A-C (SEG LVIII 1504). Le texte édité correspond au texte des 1. 1017 de l'inscription MAMA IV 297. Pourtant, le texte se poursuivait sur 17 lignes supplémentaires, caractérisées de «lacunaires " par E. Miranda même si de nombreuses lettres sont nettement visibles sur la photo publiée. De même, la face postérieure comprend une cinquantaine de lignes fortement endommagées dont cinq seulement ont été déchiffrées et éditées. Ces lignes expriment une interdiction indéterminée faite à des individus de statuts différents et suggèrent que le document qui y était gravé, à défaut d'en être nécessairement la suite, contenait, du moins, des clauses de contenu similaire à celui qui était reproduit sur la face principale. Hormis quelques variantes orthographiques, la copie de Dağmarmara permet de restituer

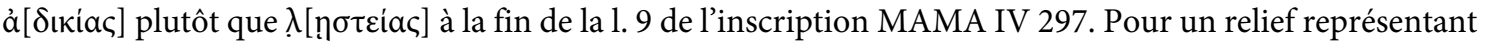
l'escorte d'un paraphylaque provenant du sanctuaire appartenant à la même communauté des Motaleis, voir supra n. 72.

${ }^{107}$ Voir déjà dans ce sens Robert 1935, 462-463. Puisqu'il est question explicitement de propriétés foncières ici, il paraît préférable de comprendre le terme $\chi \omega$ píov dans le sens de « terrain " plutôt que dans celui de « village» (cf. Schuler 1998, 49-53), quoique les dommages aient été causés dans les campagnes : il semble que ces magistrats étaient censés exercer un contrôle sur le cadastre et garantir l'intégrité des biens fonciers. 
dénonciations. Bien que cela ne soit pas dit explicitement, on peut concevoir que c'est également aux paraphylaques (ou plus exactement aux membres de leur escorte) qu'était confiée l'exécution de la peine du fouet à l'encontre des bergers de condition servile qui auraient laissé pénétrer des troupeaux dans les vignobles. Il n'est, en effet, pas nécessaire de supposer que la dénonciation des bergers ayant enfreint le règlement municipal sur les vignobles, a fortiori si c'étaient des esclaves, ait conduit à une instruction et à un procès. L'application du fouet aux bergers de condition servile en vertu du règlement pouvait faire partie des mesures de contrainte que les paraphylaques, à l'instar de la plupart des détenteurs d'une autorité publique en tant que magistrats, étaient habilités à administrer dans le cadre de leurs compétences policières pour faire respecter la loi et l'ordre public sur-le-champ, en deçà de toute procédure judiciaire ${ }^{108}$.

Comme le suggère la publication récente de poids portant les noms de paraphylaques, ces magistrats pouvaient aussi exercer occasionnellement, dans certaines cités, un contrôle sur les activités commerciales qui avaient lieu dans les campagnes. Bien que la réglementation des marchés ainsi que la surveillance des prix et des poids et mesures aient relevé en temps normal des agoranomes et parfois, pour la durée des foires qui accompagnaient les fêtes, des panégyriarques, le fait que les titres d'autres détenteurs de charges publiques apparaissent sur des poids servant d'étalons montre que ces compétences pouvaient au besoin être revêtues par d'autres magistrats, en particulier par ceux qui étaient actifs dans le domaine du maintien de l'ordre. La mention des membres du collège des irénarques sur plusieurs poids émis par la cité de Colophon - deux d'entre eux, datant de la première moitié du III ${ }^{\mathrm{e}}$ s. p.C., étant décorés sur leur face antérieure d'une couronne et portant une marque de contrôle représentant Apollon Klarios - a ainsi poussé $\mathrm{P}$. Weiss à considérer que ces magistrats, en leur qualité de principale autorité civique en matière d'ordre public, étaient chargés du bon déroulement de la panégyrie en l'honneur du dieu dans son sanctuaire de Claros, y compris des transactions commerciales qui avaient cours à cette occasion ${ }^{109}$. À la suite de la publication par ses soins d'un lot d'une quinzaine de poids portant le titre d'hipparque qui semblent devoir être attribués à Smyrne (plutôt qu'à Cyzique comme cela avait été proposé initialement), le même auteur a pu également montrer que les hipparques, parallèlement aux agoranomes, avaient manifestement exercé de façon régulière un contrôle sur les poids et mesures dans

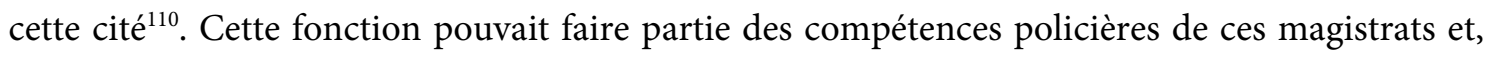
selon $\mathrm{P}$. Weiss, on aurait procédé à Smyrne à une répartition des tâches : tandis que les agoranomes se seraient occupés de la police du marché en ville, les hipparques se seraient chargés de la

\footnotetext{
${ }^{108}$ Brélaz 2005, 70-71. Un parallèle célèbre est la mesure expéditive prise par les duumvirs de la colonie de Philippes à l'encontre de l'apôtre Paul et de son compagnon Silas, qui les firent fouetter, puis emprison-

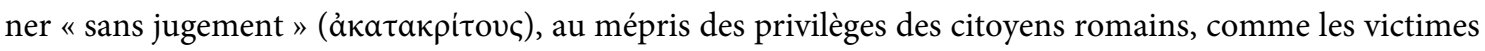
ne manquèrent pas de le leur faire remarquer : Act. Ap. 16.37-38; cf. Brélaz 2021a. Pour le recours au fouet par des agents municipaux pour s'assurer de la discipline lors de rassemblements de foule, voir le cas des mastigophores et autres rhabdophores ainsi que des agoranomes : Brélaz 2005, 171-182; Roubineau 2012. Pour la figuration de verges sur des reliefs représentant l'escorte de paraphylaques, voir supra n. 72.

${ }^{109}$ Weiss 2016, 251-253 nos II.1-2 (sur le poids SEG XLII 1038 = AE 1992, 1577, l'auteur propose de re-

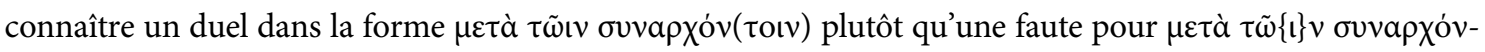
$(\tau \omega v)$, ce qui indiquerait que le collège des irénarques comprenait alors trois membres, au lieu de deux habituellement ; pour une autre interprétation, voir Brélaz 2005, 98 n. 146) ; Weiss 2018, 135-138 no. II.3.

${ }^{110}$ Weiss 1990 ; Weiss 2016, 257-265, 272-273.
} 
même mission dans la chôra ${ }^{111}$. Par ailleurs, comme dans le cas des irénarques de Colophon mentionné ci-dessus, la présence de couronnes sur deux poids attribués à Thyatire suggère peut-être que des hipparques aient pu s'acquitter spécialement de cette tâche dans cette cité lors des panégyries organisées en l'honneur d'Apollon Tyrimnos dans son sanctuaire extra-urbain ${ }^{112}$.

Le nombre d'attestations du titre de paraphylaque sur des poids est, à ce jour, très réduit, si bien que l'on ne peut postuler que le contrôle des étalons ait constitué une de leurs compétences ordinaires, comme pour les hipparques de Smyrne : on compte trois poids présentant des caractéris-

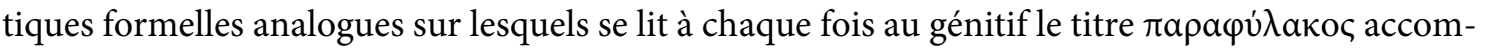
pagnant le nom du magistrat en question (on note, dans le lot, un citoyen romain portant le gentilice Aurèlios et deux pérégrins) qu'il convient d'attribuer probablement à une même cité indéterminée d'Asie Mineure occidentale, ainsi qu'un quatrième poids qui porte le nom de quatre individus au nominatif (désignés sans doute par leur cognomen uniquement, d'origine latine dans trois cas) suivi du titre $\pi \alpha \rho \alpha \varphi v \lambda a ́ \kappa \omega v$ au génitif ${ }^{133}$. Une telle rupture de construction, avec un changement de cas entre le nom du magistrat et son titre, n'est pas sans parallèle sur des poids ${ }^{114}$. S'appuyant sur une dédicace éphésienne au héros local Androklos du III s. où il est question "

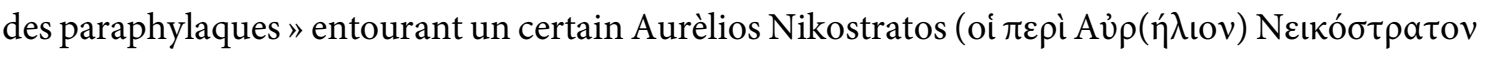

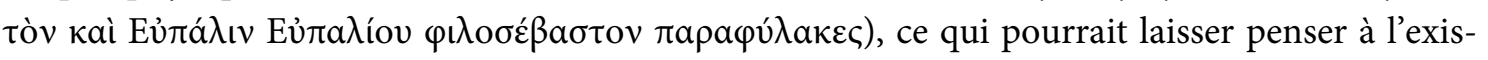
tence d'un collège de paraphylaques supérieur à deux membres, comme c'est la norme ailleurs ${ }^{115}$, P. Weiss propose d'attribuer ce dernier poids à la cité d'Éphèse. L'absence de couronnes sur ce poids ne permet pas de proposer la même interprétation que celle avancée ci-dessus à propos des irénarques de Colophon et des hipparques de Thyatire et de lier son émission à l'organisation d'une panégyrie. La nomination de quatre paraphylaques simultanément pourrait avoir répondu, dans le cas présent, à des circonstances exceptionnelles. Toujours est-il que ces quelques poids portant les noms de paraphylaques montrent que ces magistrats, dans l'exercice de leurs fonctions de surveillance territoriale, pouvaient être appelés à jouer le rôle des agoranomes lors de leurs patrouilles dans les campagnes et à représenter les autorités civiques dans la chôra, en émettant

${ }^{111}$ Contrairement à ce qui avait été proposé dans Brélaz 2005, 77-79, 148-150, on pourrait être tenté, à la lumière de ce nouveau témoignage, de reconnaître des fonctions de maintien de l'ordre aux hipparques à Smyrne (l'un d'entre eux est mis en scène accompagné de diogmites dans le Martyre de Pionios 15.1), de même qu'aux stratèges des armes, qui invoquaient Héraklès « Gardien des armes " ('O $\pi \lambda$ o $\varphi \dot{\lambda} \lambda \alpha \xi)$ comme divinité tutélaire : cf. Jones 1990.

112 Weiss 2018, 139. Pour un poids émis par un hipparque qui semble devoir être attribué à une autre cité lydienne, Philadelphie, voir Weiss 2017.

${ }^{113}$ Weiss 2016, 253-257 nos III.1-4. La lecture du titre de paraphylaque dans un monogramme figurant sur un poids provenant de Séleucie du Tigre est sujette à caution (MacDowell 1935, 256-258 ; I.Estremo Oriente 85) : voir Brélaz 2005, 400 n. 119 ; Moreau 2010, 67-69.

${ }^{114}$ Comparer I.Ephesos 558(1) ; Weiss 2018, 135-138.

${ }^{115}$ I.Ephesos 501 ; pour la chronologie relative des différentes inscriptions qui furent gravées sur la même base ainsi que des statues qui y furent successivement érigées, voir Rathmayr 2010, 31-32. On a aussi connaissance d'un ả $\chi x ı \pi \alpha \rho \varphi v ́ \lambda \alpha \xi$ à Dorylaion (OGIS 476 ; IGR IV 524). Cf. Brélaz 2005, 130-131. 
des étalons devant servir de références lors des transactions effectuées par les populations rurales $^{116}$. On ne peut prouver, en revanche, que ces poids aient été utilisés par les paraphylaques eux-mêmes comme instruments de contrôle afin de vérifier l'acquittement de taxes lors d'opérations fiscales ${ }^{117}$.

\subsection{L'hypothèse de compétences fiscales pour les paraphylaques: un réexamen de la documentation}

En raison de l'activité des paraphylaques sur l'étendue des territoires des cités d'Asie Mineure, on a parfois postulé que ces magistrats revêtaient aussi des compétences fiscales et, en particulier, qu'ils pouvaient avoir été chargés de lever les impôts et autres taxes dans les campagnes ${ }^{118}$, notamment les droits de douane perçus sur les marchandises importées au moment où celles-ci franchissaient les limites de la chôra. Pour l'époque hellénistique, comme nous l'avons vu ci-dessus, il ne semble pas - en dépit de la présence d'(h)orophylaques aux confins du territoire dans certaines cités et en dépit du fait que la surveillance territoriale pouvait y être mise à ferme - que les gardes chargés de la protection de la chôra aient été ordinairement affectés à la perception fiscale, si ce n'est peut-être de la taxe permettant justement de financer ce service. De la même façon, aucun document, pour l'époque impériale, ne semble attribuer de telles compétences aux paraphylaques. Le problème mérite néanmoins d'être examiné de plus près pour ce qui est des lois douanières des provinces d'Asie et de Lycie, dont la publication et l'affichage permanent dans les communautés locales firent suite aux dispositions prises par l'empereur Néron en 58 p.C. auxquelles Tacite fait allusion dans ses Annales et qui visaient à réprimer les abus des publicains lors de la perception des taxes sur l'importation de marchandises ${ }^{119}$.

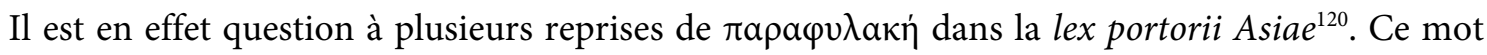
désigne à chaque fois dans le document un poste de douane et rend le latin statio. Plus précisé-

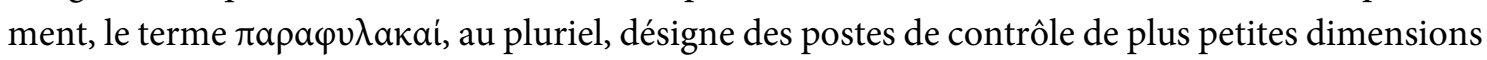
que les bureaux de douane proprement dits, appelés $\tau \varepsilon \lambda \omega \dot{\omega} v ı$, qui étaient situés aux principaux points de passage. Ces postes de contrôle étaient dispersés sur le territoire de la province pour permettre aux commerçants de déclarer les marchandises qu'ils transportaient ; y étaient en fonction des employés subalternes des publicains qui étaient chargés de vérifier, lors du passage de marchandises, que les droits de douane avaient bien été payés ${ }^{121}$. Ces $\pi \alpha \rho a \varphi v \lambda \alpha \kappa a i$ n'avaient, dans

${ }^{116}$ Comparer le poids émis par un agoranome d'une cité indéterminée au profit d'une communauté

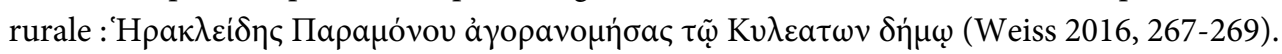

${ }^{117}$ De même, le fait qu'un sceau, provenant probablement d'une cité d'Asie Mineure (Marshall 1909, 166 no. 2 (b)), porte le nom et le titre d'un paraphylaque en exercice ne prouve pas que celui-ci ait eu des compétences fiscales. Cet objet pourrait avoir été utilisé pour authentifier des documents administratifs relevant des activités de ce magistrat dans le domaine de la surveillance territoriale, quelle qu'en ait été la nature exacte.

${ }^{118}$ Voir, par exemple, Mitchell 1993, 197.

119 Tacite, Annales 13.50-51.

${ }^{120}$ Cottier et al. 2008, 1. 31-33, 37-39, 42-44, 93-96.

${ }^{121}$ Aubert 1994, 334-342 ; Merola 2001, 209-219. Aux 1. 38-40 de la lex portorii Asiae, on introduit, de

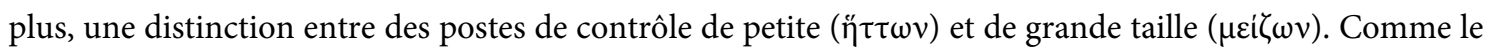

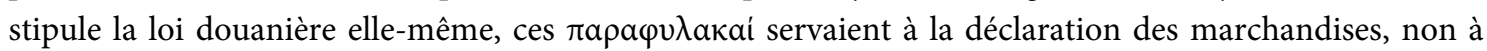


tous les cas, aucun rapport avec l'institution des paraphylaques municipaux attestée à Éphèse ainsi que dans de nombreuses cités de la province d'Asie. La loi douanière de la province de Lycie, qui est le pendant lycien de la lex portorii Asiae et dont on possède jusqu'à présent une publication préliminaire reposant sur l'exemplaire découvert à Andriakè, le port de la cité de Myra, mentionne, quant à elle, à deux reprises un $\pi \alpha \rho \alpha \varphi \dot{\lambda} \lambda \alpha \xi$. Aux 1. 41-45, il est ainsi stipulé122 :

« Celui qui achète du safran à l'intérieur [de la province] doit déclarer auprès du paraphylax le plus proche ou, si celui-ci est absent, auprès d'un magistrat la quantité achetée et le lieu où serait payée la taxe ${ }^{123}$. Les déclarations de l'ensemble devront se trouver dans

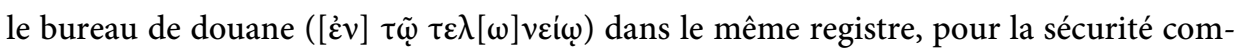
mune du publicain et du déclarant $»$.

De même, dans la clause d'affichage de la loi, aux 1. 84-87 :

« Les douaniers devront maintenir ce règlement affiché dans chaque poste de garde

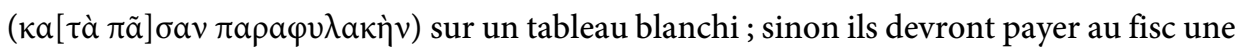
amende de dix mille drachmes. Si le paraphylax ne le maintient pas affiché de façon continue, que le gouverneur lui inflige une peine. Si le règlement relatif à l'affermage des droits de douane n'est pas affiché, les magistrats des cités doivent en informer le gouverneur ; sinon ils seront soumis à une amende pour illégalité ».

L'éditeur du texte, B. Takmer, considère qu'il convient de reconnaître dans ce $\pi \alpha \rho \alpha \varphi v ́ \lambda \alpha \xi$ le titulaire de la magistrature civique homonyme, qui est effectivement attestée dans quelques cités lyciennes ${ }^{124}$. Il y voit une confirmation d'une supposition faite il y a une trentaine d'années par M. Wörrle, qui estimait que les paraphylaques étaient les équivalents, sur le plan municipal, des magistrats fédéraux portant les titres - formés sur le même composé - d'archiphylaques et d'hypophylaques au sein du koinon lycien et qu'ils avaient donc, à l'instar de ces derniers pour laquelle la chose est prouvée par plusieurs documents, également des attributions dans le domaine de la perception fiscale en plus de leurs compétences policières (le koinon était en effet responsable de la collecte des impôts dus à Rome dans la province de Lycie et c'est lui qui organisait l'affermage des taxes douanières) $)^{125}$.

l'entreposage du produit des taxes douanières, si bien qu'il n'est pas justifié - quoique les deux termes relèvent du même champ lexical - de les assimiler aux custodiae qui sont attestées par d'autres sources avec cette fonction d'entrepôts, comme le fait Nicolet 1991, 479 avec n. 45 ; cf. Spagnuolo Vigorita 2012.

122 Takmer 2007 (SEG LVII 1666; AE 2007, 1503 dont on reproduit ici la traduction, modifiée). Pour le fonctionnement du système douanier en vigueur dans la province, dont l'organisation était laissée aux soins $\mathrm{du}$ koinon lycien et qui supposait une étroite collaboration avec les cités, voir, sur la base des autres règlements douaniers de Kaunos et de Myra, le commentaire de Chr. Marek à I.Kaunos 35, p. 200-215 ainsi que Merola 2013.

${ }^{123} \mathrm{La}$ traduction de B. Takmer s'écarte du texte grec sur ce point (ö n'est pas question du lieu de conservation de la marchandise jusqu'au paiement de la taxe ( « den Aufbewahrungsort, wo sie bis zur Entrichtung der Zollgebühr bleibt »), mais du poste où il est prévu de s'acquitter de la taxe douanière.

${ }^{124}$ Les attestations sont réunies dans Brélaz 2005, 390-392 ; on ajoutera AE 2013, 1637.

${ }^{125}$ Wörrle 1988, 149-150. Pour les compétences policières et fiscales des magistrats fédéraux lyciens, voir Brélaz 2005, 213-225. 
Cette interprétation ne semble toutefois pas pouvoir être retenue. Dans la clause d'affichage de la loi douanière, l'injonction, à la 1.85 , selon laquelle le paraphylax ne devait pas faire disparaître la copie du règlement ne ferait guère de sens s'il s'agissait d'un magistrat civique (à moins de postuler une collusion entre les fermiers de la taxe et les autorités municipales en vue d'empêcher l'accès au règlement douanier et de commettre des malversations). Du reste, les magistrats en fonction

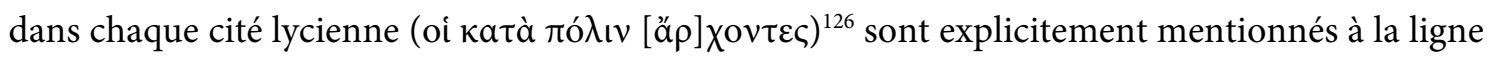
suivante pour signifier que ceux-ci devaient, dans l'intérêt public, s'assurer que le règlement serait bien affiché et que, dans le cas contraire, ils devaient en informer le gouverneur. Il en ressort que le paraphylax est distingué des magistrats civiques et n'en faisait pas partie. Le titre de paraphylax doit se comprendre dans le contexte immédiat de cette même clause : à la l. 84, il est précisé que

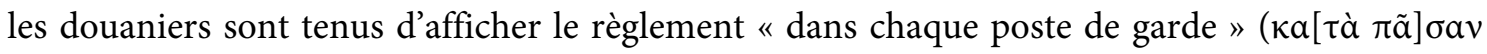
$\pi \alpha \rho a \varphi v \lambda \alpha \kappa \eta ̀ v)$. Le terme ici utilisé est le même que dans la lex portorii Asiae. Le paraphylax dont il est question à la ligne suivante et qui est sommé de laisser le règlement affiché bien en vue doit,

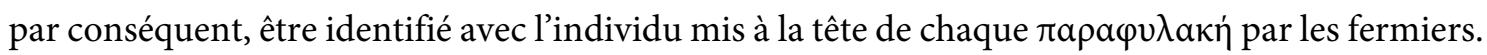
Il ne s'agit donc pas d'un magistrat civique, mais d'un employé des publicains, chargé de vérifier que la taxe a été payée. Ces tâches du paraphylax font précisément l'objet des 1. 41-45, qui portent sur l'obligation de déclarer certaines catégories de marchandises qui étaient considérées comme particulièrement précieuses (en l'occurrence du safran) et qui, pour cette raison, étaient également soumises à la taxe lorsque celles-ci étaient acquises à l'intérieur de la zone douanière qu'était la province de Lycie : pour que ces denrées puissent être transportées librement au sein de la province, il fallait, en effet, en faire une déclaration préalable « auprès du paraphylax le plus proche

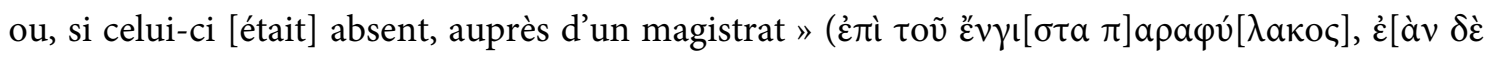

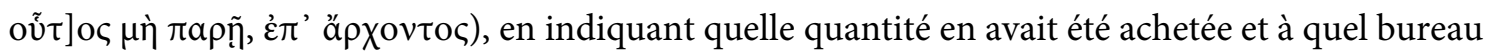
de douane la taxe serait acquittée, certainement en vue d'obtenir un laissez-passer. La désignation du paraphylax en fonction de sa localisation ( «auprès du paraphylax le plus proche ») renvoie au

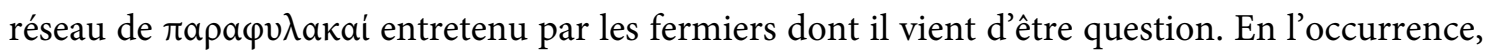
les marchands transportant du safran étaients tenus de se déclarer spontanément auprès du poste

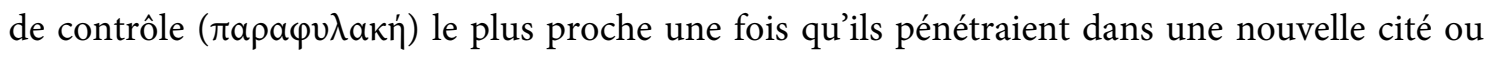
région. C'est seulement en l'absence du paraphylax que l'on était autorisé à s'adresser à un magistrat civique ${ }^{127}$, certainement en vue d'obtenir un certificat attestant que la marchandise avait été déclarée en bonne et due forme devant une autorité. La procédure est ici la même que dans la lex portorii Asiae, à cette différence près que la déclaration devait être faite, en Asie, non pas devant n'importe quel détenteur d'une charge civique, mais devant le magistrat le plus élevé dans la cité voisine (1. 40-42) :

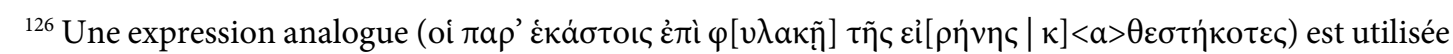
dans une lettre de Septime Sévère à la confédération lycienne récemment publiée pour désigner les magistrats en charge du maintien de l'ordre dans chacune des communautés locales, autrement dit les cités : Reger 2020.

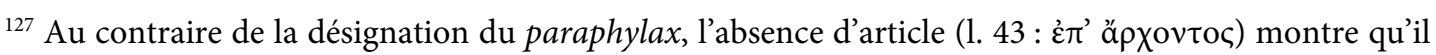
peut s'agir de n'importe quel magistrat civique (voir aussi 1.53 où il est question d'un magistrat civique et d'un esclave public, tous deux pouvant saisir les marchandises soumises à la taxe qui n'auraient pas été déclarées). On ne traduira donc pas par «l'archonte ", comme le fait B. Takmer ( "beim Archon »), car il ne s'agit pas de cette magistrature en particulier (voir, de même, sa traduction « Die in jeder Stadt tätigen Archonten » pour la 1. 86). 
« S'il ne s'y trouve [dans le poste de garde] ni un douanier ni un intendant, selon ce que prévoit ce règlement, auprès duquel on peut se signaler et auprès duquel on peut faire la déclaration avant de procéder à l'importation, lorsque ce cas de figure se présente, on est tenu de faire la déclaration dans la cité la plus proche de ce lieu, auprès de la personne

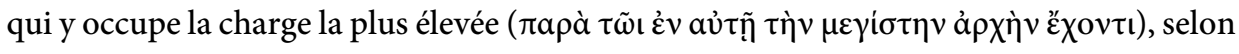
ce qui est stipulé dans le règlement $»^{128}$.

En revanche, ni dans le règlement lycien, ni dans la loi d'Asie, la clause n'indique comment l'information devrait ensuite être transmise par le magistrat aux employés des fermiers, ni surtout comment les paraphylakes pouvaient avoir l'assurance que la taxe serait effectivement payée, puisqu'au contraire des marchandises qui étaient importées en Lycie ou exportées de Lycie et qui étaient soumises à la taxe douanière lors de leur franchissement des frontières provinciales, la déclaration portant sur le commerce du safran à l'intérieur de la province ne comprenait qu'un engagement de la part du commerçant à payer la taxe en question à l'un des bureaux de douane qu'il rencontrerait $(1.43 \text { : ö } \pi 0 v \text { aủंò } \mu \dot{\varepsilon} \lambda \lambda \varepsilon ı \tau[\varepsilon \lambda] \omega[\nu \varepsilon \tilde{\sigma} \sigma] \alpha \iota)^{129}$. On s'est borné à prescrire que les déclarations reçues par les paraphylakes ou par les magistrats civiques approchés par les commerçants devaient, en fin de compte, être collectées pour être retranscrites dans un registre unique déposé au bureau de douane - correspondant certainement au siège principal des fermiers - à des fins de vérification.

Ce même sens du mot paraphylax, désignant un employé œuvrant dans un poste de contrôle chargé de vérifier le paiement de taxes, se rencontre précisément dans une autre inscription éphésienne, également d'époque néronienne, relevant de la sphère fiscale : il s'agit de la dédicace du

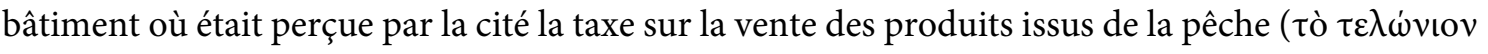
$\tau \tilde{\eta} \varsigma$ i $\chi \theta \dot{0} \kappa \tilde{\eta} \varsigma)^{130}$. Le bâtiment fut offert par la corporation des pêcheurs et des poissonniers, qui s'en servaient probablement pour la vente en gros de leur marchandise une fois la taxe prélevée ${ }^{131}$. Parmi les dizaines de souscripteurs ayant contribué à l'érection du bâtiment, on relève deux individus qualifiés chacun de $\pi \alpha \rho \alpha \varphi v ́ \lambda \alpha \xi$ (b, 1. 32, 34). Comme ceux-ci - au contraire des autres personnes identifiées dans la liste soit par leur nom personnel suivi du patronyme, soit par leur tria nomina - ne sont désignés que par des noms uniques (Фó $\beta$ ßo et $\Sigma \varepsilon \kappa o v ̃ v \delta o \varsigma)$, quoique l’un d'eux soit d'inspiration latine, on en conclut qu'il s'agissait d'esclaves et que ce ne pouvaient donc être des membres de l'élite civique, comme les autres magistrats revêtant la magistrature de paraphylaque que l'on connaît par ailleurs à Éphèse. Associés à un $\tau \varepsilon \lambda \omega \dot{\omega}$ เov, comme les paraphylakes employés par les fermiers des portoria d'Asie et de Lycie, ces deux esclaves, qui étaient au service de la cité ou des corporations qui y étaient actives, devaient, dans ce cas aussi, servir de contrôleurs des taxes sur la pêche. On constate donc que le nom d'agent $\pi \alpha \rho \alpha \varphi v ́ \lambda \alpha \xi$ peut désigner des réalités fort différentes. S'il renvoie le plus souvent à un titre de magistrature dans les cités d'Asie Mineure à l'époque impériale, comme nous l'avons vu jusqu'à présent, il peut servir à désigner plus généralement, dans d'autres contextes, un garde, spécialement dans la langue grecque tardive, ou un

\footnotetext{
${ }^{128}$ Les mêmes dispositions sont répétées aux 1. 117-120 dans une clause supplémentaire.

${ }^{129}$ Il est vraisemblable que l'on ait dû choisir pour ce faire le bureau de douane ou le poste de garde le plus proche, comme le prévoit la lex portorii Asiae, 1. 40-45, 48-50.

${ }^{130}$ I.Ephesos 20.

${ }^{131}$ Lytle 2012.
} 
contrôleur ${ }^{132}$. À l'époque byzantine, le titre de $\pi \alpha \rho a \varphi v ́ \lambda \alpha \xi$ désigne ainsi tantôt un officier affecté à une place forte, tantôt un fonctionnaire du fisc subordonné au kommerkiarios ${ }^{133}$. Le fait que les employés des postes de contrôle du paiement des taxes douanières soient qualifiés de paraphylakes ne saurait, dans tous les cas, constituer une preuve que les magistrats homonymes possédaient des compétences dans le domaine fiscal.

\section{En guise de bilan : la surveillance du territoire des cités d'Asie Mineure, de l'affermage d'une pres- tation d'intérêt public à la charge civique}

Ce parcours à travers une documentation lacunaire et dispersée ne permet pas de reconstituer dans tous ses détails l'organisation administrative et financière du service d'intérêt public qu'était la surveillance du territoire dans les cités grecques aux époques hellénistique et impériale. Il autorise néanmoins des réflexions sur les stratégies élaborées par les cités pour financer le service de protection de leur territoire, aussi bien en cas de crise, où des expédients devaient être trouvés dans l'urgence, qu'en temps ordinaire, où ces communautés étaient confrontées à un manque chronique de liquidités. En dehors des cas où la mission consistant à patrouiller dans la chôra pouvait être confiée aux organisations éphébiques ou des régions où étaient stationnées des troupes royales dans le but de contrôler le territoire, les cités, voire les rois eux-mêmes, étaient, au cours de l'époque hellénistique, contraints de prévoir, sinon une rémunération, du moins un dédommagement pour les personnes qui se chargeraient, au nom de la collectivité, de la phylakè tès chôras. Ces individus pouvaient être des citoyens ou des résidents étrangers. Suivant les cas, le service de surveillance territoriale pouvait être attribué à un groupe de personnes contre des exemptions fiscales, être mis à ferme contre le droit de participer à la perception de taxes permettant ainsi à l'adjudicataire de se rémunérer ou faire l'objet d'un contrat prévoyant la rétribution du prestataire par le biais des fonds publics ou d'autres opérations financières. La diversité de ces solutions est conforme à ce que l'on sait de la malléabilité de l'organisation financière des cités grecques et suppose, dans tous les cas, la participation de particuliers ${ }^{134}$.

L'évolution de la façon dont fut envisagée la surveillance du territoire dans les cités d'Asie Mineure à l'époque impériale romaine reflète, pour sa part, certaines des principales transformations institutionnelles, économiques et sociales que connurent ces communautés au cours de cette période. Le premier élément à relever est la substitution de la régie directe à l’affermage ou au contrat public dans la gestion du service de surveillance territoriale. Une évolution semblable s'observe dans le domaine de la perception fiscale où, progressivement, des fonctionnaires impériaux et des services administratifs prirent la place des publicains et des sociétés privées auxquels avait été déléguée, jusqu'alors, la tâche de lever les taxes et les impôts. À défaut toutefois de structures impériales dévolues à la sécurité publique qui auraient été déployées à grande échelle à l'intérieur des provinces, le maintien de l'ordre au jour le jour demeura du ressort des communautés locales de l'Empire et la magistrature de paraphylaque, en l'espèce, qu'on relève dans nombre de cités

\footnotetext{
${ }^{132}$ Brélaz 2005, 123-124 ; Moreau 2010, 65-80 (pour les inscriptions syriennes tardo-antiques qui y sont examinées, voir IGLS III/1 884 et SEG LXV 1688). Voir également, au cours de l'époque impériale, d'éventuels gardiens de sanctuaires portant ce titre à Samos et à Milet, qui paraissent revêtir une fonction de nature sacerdotale : Brélaz 2005, 138-139.

${ }^{133}$ Kazhdan 1991 ; Cheynet 2005.

${ }^{134}$ Migeotte 2014, 278-299.
} 
d'Asie Mineure à l'époque impériale, ne fut pas créée par les autorités romaines. Au contraire de ce qui prévalut pour les irénarques, dont la nomination - pour quelques décennies du moins au cours du II ${ }^{\mathrm{e}}$ s. p.C. dans la province d'Asie - fut soumise au contrôle du proconsul à la suite de violences et d'exactions répétées $-{ }^{135}$, les paraphylaques étaient, comme tous les autres magistrats locaux, choisis par la boulè dans les cités. S'il ne paraît pas que les autorités romaines soient intervenues dans l'établissement de cette fonction civique, qui n'avait aucun lien organique ou hiérarchique avec les structures administratives ou militaires impériales ${ }^{136}$, sa diffusion, en revanche, put être encouragée par elles. Dans la plupart des cas, cependant, cette fonction dut être adoptée par les cités par mimétisme avec leurs voisines, ce procédé se vérifiant pour quantité d'autres institutions et pratiques s'étant généralisées dans les communautés locales d'Asie Mineure. Les cités furent sans doute d'autant plus promptes à se doter, dès le courant du $\mathrm{I}^{\text {er }}$ s. p.C., d'une fonction civile explicitement chargée de la surveillance territoriale - comme elles le feront quelques décennies plus tard avec la charge de répression criminelle qu'est l'irénarchie - qu'elles avaient été, pour la plupart, privées de leurs magistratures militaires à l'époque augustéenne du fait de la disparition des armées civiques. Dans les cités où les anciennes magistratures militaires ne furent pas maintenues, même au prix d'une nette diminution de leurs compétences, désormais limitées à des opérations de maintien de l'ordre, la nouvelle charge de paraphylaque joua ce rôle de surveillance territoriale.

Le fonctionnement de la magistrature de paraphylaque illustre un autre changement majeur, de nature socio-économique cette fois, qui affecta les cités grecques au cours de l'époque impériale : il s'agit du rôle joué par les détenteurs de charges publiques dans le financement des services qui leur étaient confiés. Comme le montrent plusieurs des exemples discutés dans cette étude, il n'était pas rare que les paraphylaques, qui étaient issus des milieux sociaux les plus en vue dans leur cité, prennent en charge les dépenses liées à l'exercice de leur fonction sur leurs fonds personnels, voire profitent de leur stature de magistrat pour offrir à la collectivité des bienfaits supplémentaires, qui n'étaient - strictement parlant - pas nécessaires à l'accomplissement de leur tâche de surveillance territoriale. À l'instar des autres magistrats, les paraphylaques agissaient en évergètes. Ces contributions volontaires ne signifient pas que les cités n'aient prévu aucun budget en amont pour le service de surveillance territoriale ${ }^{137}$. Il était néanmoins devenu à ce point habituel pour les notables s'acquittant d'une charge publique dans ces cités à l'époque impériale de consacrer une partie de leur fortune à l'entretien du service qu'ils se voyaient remettre que les paraphylaques aussi durent ressentir les effets de cette attente et se plier à cette forme de contrainte morale.

Comme nous l'avons vu dans la première partie de cette étude, les activités liées à la surveillance du territoire pouvaient, au cours de l'époque hellénistique, accompagner ou inclure des opérations de perception fiscale. Bien que la défense du territoire rural et la collecte des impôts aient, en principe, fait l'objet dans les cités grecques de deux services distincts et que des magistrats ad hoc aient été nommés pour s'occuper de chacun d'eux, le fait que ces deux secteurs de l'action publique aient concerné le même espace géographique, à savoir les campagnes, a pu mener, dans

${ }^{135}$ Voir supra n. 82.

${ }^{136}$ Cela vaut aussi pour l'irénarchie : contra Yannakopulos 2003. Pour le statut de cette fonction dans la province d'Égypte, voir Sänger 2010.

${ }^{137}$ Sur la part respective des contributions évergétiques et de la planification budgétaire dans l’administration financière des cités au cours de l'époque impériale, voir Chankowski 2015. 
certains cas, à des collaborations, voire à la mutualisation des moyens utilisés pour s'acquitter de ces missions. C'était, semble-t-il, en partie le cas sur les territoires respectifs de Milet et d'Héraclée du Latmos au début du II ${ }^{\mathrm{e}}$ s. a.C. où - selon l'interprétation que nous avons proposée ci-dessus les fermiers des taxes qui étaient perçues dans la chôra, et plus particulièrement à ses limites, étaient accompagnés de gardes et de patrouilleurs. Aucun document ne permet d'établir, en revanche, que les paraphylaques - indépendamment du contrôle qu'ils pouvaient exercer, en tant que représentants des autorités civiques, sur les activités économiques dans les campagnes - aient eu des attributions fiscales dans les cités d'Asie Mineure au cours de l'époque impériale.

Néanmoins, la conservation de la domination de Rome sur son empire reposait, pour une large part, sur la régularité avec laquelle les impôts étaient payés. En raison de l'hostilité que la levée des taxes et impôts pouvait provoquer au sein des populations provinciales et des heurts qui pouvaient s'ensuivre, des problèmes de maintien de l'ordre pouvaient se présenter lors des opérations de perception fiscale. L'association de membres des forces de l'ordre et d'employés ou de fonctionnaires chargés de la perception fiscale est ainsi attestée à plusieurs reprises dans l'Empire. Soldats et douaniers se côtoyaient, du reste, dans les endroits stratégiques tels que les ports, les portes des villes, les principales voies de communication, les limites extérieures des provinces, où postes de garde militaires et postes de douane - tous deux appelés stationes en latin - pouvaient coexister, voire être contigus ${ }^{138}$. Certains bâtiments pouvaient même servir tout à la fois de locaux de perception des taxes et péages et de postes de surveillance pour de petits contingents militaires. Mais les soldats détachés dans ces postes de garde à travers les provinces, au premier chef les beneficiarii, n'étaient eux-mêmes, en principe, pas habilités à percevoir les taxes, et les opérations douanières, qui relevaient des compétences des sociétés de publicains ou des fonctionnaires impériaux, n'étaient normalement pas placées sous le contrôle de l'armée ${ }^{139}$. Toutefois, comme l'illustre la documentation papyrologique et talmudique, des soldats pouvaient intervenir directement dans la levée de certains impôts et taxes, surtout ceux qui étaient perçus au profit de l'armée tels que l'annone militaire ou les réquisitions liées à l'acheminement de courriers officiels ${ }^{140}$. Dans la province d'Égypte, la présence de soldats aux côtés de fonctionnaires impériaux et locaux chargés de la perception fiscale est épisodiquement attestée, sans qu'il soit possible de conclure que cette collaboration ait résulté d'une exigence administrative ${ }^{141}$. De plus, à l'échelon local, les fonctionnaires actifs dans la perception des impôts et taxes dans cette même province, tels que les arabotoxotai et les erèmophylakes, avaient également des compétences dans le domaine de la surveillance territoriale et du maintien de l'ordre ${ }^{142}$. Il semble, par ailleurs, qu'à la manière de la taxe perçue pour l'entretien des (h)orophylaques à Héraclée du Latmos, comme nous l'avons relevé plus haut, ceuxci levaient aussi une taxe destinée à financer leur propre prestation ${ }^{143}$.

\footnotetext{
${ }^{138}$ France - Nelis-Clément 2014.

${ }^{139}$ Nelis-Clément 2000, 252-259.

${ }^{140}$ Isaac 1992, 282-304 ; Nelis-Clément 2000, 73-74, 176-177, 194, 209, 211, 217, 222-223.

${ }^{141}$ Alston 1995, 79-80 ; Capponi 2005, 123-129. À l'époque ptolémaïque, à l'inverse, les forces de police participaient régulièrement à la levée des impôts dans les campagnes : Bauschatz 2013, 281-327.

${ }^{142}$ Hennig 2004.

${ }^{143}$ Carrié 2004.
} 
Quoi qu'il en soit de la situation en vigueur dans la province d'Égypte, cela ne saurait constituer une preuve que les magistrats en charge de la surveillance territoriale dans les cités de Grèce ou d'Asie Mineure aient également eu pour tâche de lever les impôts lors de leurs patrouilles dans les campagnes. Cela est d'autant moins plausible que, parallèlement à la magistrature de paraphylaque, fut créée dans ces cités une fonction spécialement dédiée à la perception fiscale : la charge de dékaprôtos ${ }^{144}$. La fonction, qui était considérée comme une liturgie et pouvait être revêtue pour plusieurs années d'affilée, est attestée dans la province d'Achaïe depuis l'époque augustéenne et en Macédoine depuis le courant du ${ }^{\text {er }}$ s. p.C. ${ }^{145}$. Bien qu'elle soit attestée en Lydie dès le milieu du $\mathrm{I}^{\mathrm{er}}$ s. p.C. ${ }^{146}$, sa diffusion paraît avoir été plus tardive en Asie Mineure, où elle ne se généralisa qu'au milieu du $\mathrm{II}^{\mathrm{e}}$ s. p.C. Le décalage que l'on observe dans l'introduction de cette charge selon les provinces témoigne certainement de la diversité de l'organisation des systèmes fiscaux dans ces dernières, l'affermage des impôts fonciers ayant perduré dans certaines provinces plus longtemps que dans d'autres où celui-ci fut remplacé par une régie directe exercée par les communautés locales. Bien que Chr. Samitz ait récemment proposé de voir dans la fonction de dékaprôtos une création expresse des autorités romaines ${ }^{147}$, le fait que celle-ci n'ait pas été uniformément répandue dans les provinces anatoliennes, par exemple en Asie où certaines cités n'introduisirent manifestement pas cette charge, ou tardivement, montre que c'est la diversité des situations locales qui, en la matière, a prévalu. Cela dissuade, en particulier, de considérer que cette charge ait été imposée verticalement aux communautés locales par les autorités impériales. Comme pour les fonctions de paraphylaque ou d'irénarque, la charge de dékaprôtos fut vraisemblablement adoptée progressivement par les cités grecques à la suite d'influences réciproques, la levée des impôts dans les cités où celle-ci n'est pas attestée étant confiée à d'autres magistrats ou liturges. Quoiqu'elle n'ait pas eu de lien organique avec l'appareil d'État romain et bien qu'elle n'ait pas dépendu de l'administration provinciale, la charge de dékaprôtos - tout comme celle de paraphylaque pour ce qui relevait de la sécurité publique sur le territoire des communautés locales - contribuait activement au maintien de l'ordre politique, social et économique sur lequel reposait la domination impériale romaine dans les provinces d'Asie Mineure. En permettant aux communautés locales d'exercer ces compétences qui leur étaient pourtant directement profitables, les autorités romaines se déchargeaient d'autant. L'autonomie étendue dont jouissaient les cités sous le régime provincial était donc, dans ces domaines cruciaux qu'étaient le maintien de l'ordre et la fiscalité, une condition nécessaire à la préservation de l'hégémonie romaine et un trait caractéristique de la gouvernance impériale romaine, comme le célèbre Aelius Aristide dans son Éloge à Rome: « Les habitants les plus importants et les plus puissants de chaque endroit gardent pour vous leur propre patrie, si bien que vous tenez les cités de deux manières : à partir d'ici, et une par une grâce à eux ${ }^{148}$.

\footnotetext{
${ }^{144}$ Samitz 2013. Piérie ? 73/4 p.C.).

${ }^{146}$ AE 20121479 = SEG LXII 918 A, 1.19 et 918 B, 1.9 (Julia Gordos, 69/70 p.C.).

${ }^{147}$ Samitz 2013, 35-36.

${ }^{148}$ Aelius Aristide. Or. 26.64 (trad. Pernot 1997).
}

${ }^{145}$ AE 2014, 1196 (Messène, époque augustéenne) ; SEG LX 644 = AE 2012, 1295 (cité de Phylakai en 


\section{Bibliographie}

Akyürek Şahin 2012

Alston 1995

Anderson 1897

Aubert 1994

Bauschatz 2013

Blanco-Pérez 2013

Bouchon 2014

Boulay 2014

Boulay - Pont 2014

Brélaz 2005

Brélaz 2008

Brélaz 2011

Brélaz 2015

Brélaz 2021a

Brélaz 2021b
N. E. Akyürek Şahin, Unter der Statthalterschaft des Rufius Varenus in Bithynien ehren die Trikkeanoi ihren Wohltäter Achaïkos, Gephyra 9, 2012, 92-100.

R. Alston, Soldier and Society in Roman Egypt. A Social History, London - New York 1995.

J. G. C. Anderson, A Summer in Phrygia: I, JHS 17, 1897, 396-424.

J.-J. Aubert, Business Managers in Ancient Rome, Leiden - New York 1994.

J. Bauschatz, Law and Enforcement in Ptolemaic Egypt, Cambridge 2013.

A. Blanco-Pérez, C. Claudius Lucianus: An Eirenarch from Akmoneia Selected by the Proconsul M. Sulpicius Crassus. A Note on SEG 56.1493, ZPE 186, 2013, 190-194.

R. Bouchon, Démophilos de Doliché, Paul-Émile et les consequences de la troisième guerre de Macédoine à Gonnoi, Topoi 19/2, 2014, 483-513.

Th. Boulay, Arès dans la cité. Les poleis et la guerre dans l'Asie Mineure hellénistique, Pisa - Roma 2014.

Th. Boulay - A.-V. Pont, Chalkètôr en Carie, Paris 2014.

C. Brélaz, La sécurité publique en Asie Mineure sous le Principat ( ${ }^{\text {er }}$ - III ${ }^{e}$ s. ap. J.-C.). Institutions municipales et institutions impériales dans l'Orient romain, Basel 2005.

C. Brélaz, L'adieu aux armes: la défense de la cité grecque dans l'empire romain pacifié, in: C. Brélaz - P. Ducrey (edd.), Sécurité collective et ordre public dans les sociétés anciennes, Vandoeuvres-Genève 2008, 155-204.

C. Brélaz, Aelius Aristide (Or. 50.72-93) et le choix des irénarques par le gouverneur: à propos d'une inscription d'Acmonia, in: N. Badoud (ed.), Philologos Dionysios. Mélanges offerts au professeur Denis Knoepfler, Genève 2011, 603-637.

C. Brélaz, Cultura militare e identità collettive nelle città greche sotto l'Impero romano, in: E. Franchi - G. Proietti (edd), Guerra e memoria nel mondo antico, Trento 2015, 259-286.

C. Brélaz, The Provincial Contexts of Paul's Imprisonments: Law Enforcement and Criminal Procedure in the Roman East, Journal for the Study of the New Testament 43, 2021, 485-507.

C. Brélaz, Deviating Soldiers: Officials on the Move and Local Communities at Risk in Roman Asia Minor and Greece, in: Cl. Moatti E. Chevreau (edd.), L'expérience de la mobilité de l'Antiquité à nos jours, entre précarité et confiance, Bordeaux 2021, 171-187. 
Burton 2000

Capponi 2005

Carrié 2004

Chaniotis 2008

Chankowski 2011

Chankowski 2015

Cheynet 2005

Cottier et al. 2008

Couvenhes 2011

D'Andria et al. 2012

D’Andria et al. 2016

Dmitriev 2005

Drecoll 1997

Fachard 2012

Faraguna 2005

Fernoux 2011
G. P. Burton, The Resolution of Territorial Disputes in the Provinces of the Roman Empire, Chiron 30, 2000, 195-215.

L. Capponi, Augustan Egypt. The Creation of a Roman Province, New York - London 2005.

J.-M. Carrié, Portarenses (douaniers), soldats et annones dans les archives de Douch, Oasis Major, in: C. Balmelle et al. (edd.), Mélanges d'Antiquité Tardive. Studiola in honorem Noël Duval, Turnhout 2004, 261-274.

A. Chaniotis, Policing the Hellenistic Countryside: Realities and Ideologies, in: C. Brélaz - P. Ducrey (edd.), Sécurité collective et ordre public dans les sociétés anciennes, Vandoeuvres-Genève 2008, 103-153.

A. Chankowski, L'éphébie hellénistique: étude d'une institution civique dans les cités grecques des îles de la Mer Égée et de l'Asie Mineure, Paris 2011.

V. Chankowski, L'apport des sources impériales à la connaissance des finances des cités grecques, Topoi 20/2, 2015, 435-461.

J.-Cl. Cheynet, Note sur le comte et le paraphylax d'Abydos (VI ${ }^{\mathrm{e}}$ VIII ${ }^{\mathrm{e}}$ siècle), in: M. Aurell - Th. Deswarte (edd.), Famille, violence et christianisation au Moyen Âge. Mélanges offerts à Michel Rouche, Paris 2005, 377-386.

M. Cottier et al. (edd.), The Customs Law of Asia, Oxford 2008.

J.-Chr. Couvenhes, Péripoloi, kryptoi et hypaithroi de la cité athénienne, in: J.-Chr. Couvenhes et al. (edd.), Pratiques et identités culturelles des armées hellénistiques du monde méditerranéen, Bordeaux 2011, 295-306.

F. D'Andria et al. (edd.), Hierapolis di Frigia V. Le attività delle campagne di scavo e restauro 2004-2006, Istanbul 2012.

F. D'Andria et al. (edd.), Hierapolis di Frigia VIII, 2. Le attività delle campagne di scavo e restauro 2007-2011, Istanbul 2016.

S. Dmitriev, City Government in Hellenistic and Roman Asia Minor, Oxford 2005.

C. Drecoll, Die Liturgien im Römischen Kaiserreich des 3. und 4. Jh. n. Chr. Untersuchung über Zugang, Inhalt und wirtschaftliche Bedeutung der öffentlichen Zwangsdienste in Ägypten und anderen Provinzen, Stuttgart 1997.

S. Fachard, La défense du territoire. Étude de la chôra érétrienne et de ses fortifications, Gollion 2012.

M. Faraguna, Terra pubblica e vendite di immobili confiscati a Chio nel V secolo a.C., Dike 8, 2005, 89-99.

H. Fernoux, Le Demos et la Cité. Communautés et assemblées populaires en Asie Mineure à l'époque impériale, Rennes 2011. 
Ferrary 2014

Fischer-Bovet 2014

Fournier 2010

France - Nelis-Clément 2014

Fuhrmann 2012

Hauken 1998

Haussoullier 1879

Haussoullier 1917

Heller - Suspène 2019

Helly 2008

Helly - Tziafalias 2013

Hennig 2004

Hennig 2006

Homoth-Kuhs 2005

Horstkotte 1996

Isaac 1992

Jones 1990

Jördens 2011
J.-L. Ferrary, Les mémoriaux de délégations du sanctuaire oraculaire de Claros, d'après la documentation conservée dans le Fonds Louis Robert, Paris 2014.

Chr. Fischer-Bovet, Army and Society in Ptolemaic Egypt, Cambridge 2014.

J. Fournier, Entre tutelle romaine et autonomie civique. L'administration judiciaire dans les provinces hellénophones de l'empire romain (129 av. J.-C. - 235 apr. J.-C.), Athènes 2010.

J. France - J. Nelis-Clément, Tout en bas de l'empire. Les stationes, lieux de contrôle et de représentation du pouvoir, in: J. France J. Nelis-Clément (edd.), La statio. Archéologie d'un lieu de pouvoir dans l'empire romain, Bordeaux 2014, 117-245.

C. J. Fuhrmann, Policing the Roman Empire: Soldiers, Administration, and Public Order, Oxford 2012.

T. Hauken, Petition and Response. An Epigraphic Study of Petitions to Roman Emperors 181-249, Bergen 1998.

B. Haussoullier, Inscriptions de Chio, BCH 3, 1879, 230-255.

B. Haussoullier, Traité entre Delphes et Pellana, Paris 1917.

A. Heller - A. Suspène, C. Asinius Gallus hagnos à Temnos: la rhétorique civique face au pouvoir romain, in: A. Heller et al. (edd.), Philorhômaios kai philhellèn. Hommage à Jean-Louis Ferrary, Genève 2019, 501-520.

B. Helly, Encore le blé thessalien. Trois décrets de Larisa (IG IX 2, 506) accordant aux Athéniens licence d'exportation et réduction des droits de douane sur leurs achats de blé, in: B. Virgilio (ed.), Studi ellenistici XX, Pisa - Roma 2008, 25-108.

B. Helly - A. Tziafalias, Décrets inédits de Larisa organisant la vente de terres publiques attribuées aux cavaliers, Topoi 18/1, 2013, 135-249.

D. Hennig, Arabotoxotai und Eremophylakes im römischen Ägypten, Chiron 34, 2004, 267-284.

D. Hennig, Oreophylakes in Ägypten, Chiron 36, 2006, 1-10.

C. Homoth-Kuhs, Phylakes und Phylakon-Steuer im griechisch-römischen Ägypten. Ein Beitrag zur Geschichte des antiken Sicherheitswesens, München - Leipzig 2005.

H. Horstkotte, Systematische Aspekte der munera publica in der römischen Kaiserzeit, ZPE 111, 1996, 233-255.

B. Isaac, The Limits of Empire, The Roman Army in the East, Oxford $1992^{2}$.

C. P. Jones, Heracles at Smyrna, AJN 2, 1990, 65-76.

A. Jördens, Eine kaiserliche Konstitution zu den Rechtsprechungskompetenzen der Statthalter, Chiron 41, 2011, 327-356. 
Kayser 2011

Kazhdan 1991

Kennell 2012

Kirbihler 2012

Kleijwegt 1994

Leschhorn 1993

Lytle 2012

MacDowell 1935

Macridy 1905

Macridy 1912

Magie 1950

Marek - Adak 2016

Marshall 1909

Mason 1974

Merola 2001

Merola 2013
Fr. Kayser, Les (h)orophylaques, gardiens des montagnes dans les mondes grecs aux époques hellénistique et romaine ?, in: S. BertierFoglar - Fr. Bertrandy (edd.), La montagne: pouvoirs et conflits de l'Antiquité au XXI siècle, Chambéry 2011, 17-30.

A. Kazhdan, The Oxford Dictionary of Byzantium, 1991, s. v. Paraphylax.

N. M. Kennell, Who Were the Neoi ?, in: P. Martzavou - N. Papazarkadas (edd.), Epigraphical Approaches to the Post-Classical Polis, Fourth Century BC to Second Century AD, Oxford 2012, 217-232.

Fr. Kirbihler, Un cursus honorum à Éphèse ? Quelques réflexions sur la succession des magistratures de la cité à l'époque romaine, in: P. Goukowsky - Chr. Feyel (edd.), Folia Graeca in honorem Edouard Will, Historica, Nancy 2012, 67-107.

M. Kleijwegt, 'Voluntarily, but Under Pressure'. Voluntarity and Constraint in Greek Municipal Politics, Mnemosyne 47, 1994, 64-78.

W. Leschhorn, Antike Ären. Zeitrechnung, Politik und Geschichte im Schwarzmeerraum und in Kleinasien nördlich des Tauros, Stuttgart 1993.

E. Lytle, A Customs House of Our Own: Infrastructure, Duties and a Joint Association of Fishermen and Fishmongers (IK, 11.1a-Ephesos, 20), in: V. Chankowski - P. Karvonis (edd.), Tout vendre, tout acheter. Structures et équipements des marchés antiques, Bordeaux 2012, 213-224.

R. H. MacDowell, Stamped and Inscribed Objects from Seleucia on the Tigris, Ann Arbor 1935.

Th. Macridy, Altertümer von Notion, JÖAI 8, 1905, Hauptblatt, 155-173.

Th. Macridy, Antiquités de Notion II, JÖAI 15, 1912, Hauptblatt, 36-67.

D. Magie, Roman Rule in Asia Minor to the End of the Third Century after Christ, Vol. I-II, Princeton 1950.

Chr. Marek - M. Adak, Epigraphische Forschungen in Bithynien, Paphlagonien, Galatien und Pontos, Istanbul 2016.

F. H. Marshall, Some Recent Acquisitions of the British Museum, JHS 29, 1909, 151-167.

H. J. Mason, Greek Terms for Roman Institutions. A Lexicon and Analysis, Toronto 1974.

G. D. Merola, Autonomia locale, governo imperiale. Fiscalità e amministrazione nelle province asiane, Bari 2001.

G. D. Merola, Leggi doganali d'Asia: testi a confronto, MediterrAnt 16, 2013, 455-470. 
Migeotte 1992

Migeotte 2014

Mili 2015

Mitchell 1993

Moreau 2010

Müller 1976

Nelis-Clément 2000

Nicolet 1991

Oetjen 2014

Öztürk 2016

Pernin 2014

Pernot 1997

Piejko 1988

Pont 2017

Ramsay 1895-1897

Ramsay 1927

Rathmayr 2010

Reger 2020
L. Migeotte, Les souscriptions publiques dans les cités grecques, Genève - Québec 1992.

L. Migeotte, Les finances des cités grecques aux périodes classique et hellénistique, Paris 2014.

M. Mili, Religion and Society in Ancient Thessaly, Oxford 2015.

S. Mitchell, Anatolia. Land, Men, and Gods in Asia Minor, I, The Celts in Anatolia and the Impact of Roman Rule, Oxford 1993.

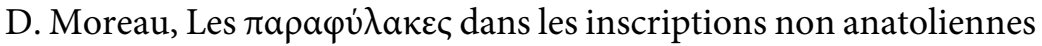
de l'Antiquité ( ${ }^{\mathrm{er}}-\mathrm{VI}^{\mathrm{e}}$ siècle ap. J.-C.). État de la question, hypothèses et pistes de recherche, Archaeologia Bulgarica 14, 2010, 65-80.

H. Müller, Milesische Volksbeschlüsse. Eine Untersuchung zur Verfassungsgeschichte der Stadt Milet in hellenistischer Zeit, Göttingen 1976.

J. Nelis-Clément, Les beneficiarii: militaires et administrateurs au service de l'Empire ( ${ }^{\mathrm{er}}$ s. a.C. - VI ${ }^{\mathrm{e}}$ s. p.C.), Bordeaux 2000.

$\mathrm{Cl}$. Nicolet, Le monumentum Ephesenum et les dîmes d'Asie, BCH 115, 1991, 465-480.

R. Oetjen, Athen im dritten Jahrhundert v. Chr. Politik und Gesellschaft in den Garnisonsdemen auf der Grundlage der inschriftlichen Überlieferung, Duisburg 2014.

B. Öztürk, A Funerary Inscription from Herakleia Pontike: Ephebarchos and Paraphylax Aurelius Artemonianos Menios, ZPE 199, 2016, 99-103.

I. Pernin, Les baux ruraux en Grèce ancienne. Corpus épigraphique et étude, Lyon 2014.

L. Pernot, Éloges grecs de Rome, Paris 1997.

F. Piejko, The Inscriptions of Icarus-Failaka, C\&M 39, 1988, 89-116.

A.-V. Pont, Dernières mentions des magistratures et des liturgies traditionnelles dans les cités d'Asie mineure: habitus épigraphique et vie institutionnelle locale à la fin du $\mathrm{III}^{\mathrm{e}}$ et au début du $\mathrm{IV}^{\mathrm{e}}$ siècle, Chiron 47, 2017, 35-55.

W. M. Ramsay, The Cities and Bishoprics of Phrygia, Oxford 18951897, 2 vols.

W. M. Ramsay, Asianic Elements in Greek Civilisation. The Gifford Lectures in the University of Edinburgh 1915-16, London 1927.

E. Rathmayr, Die Präsenz des Ktistes Androklos in Ephesos, AAWW 145, 2010, 19-60.

G. Reger, A Letter of Septimius Severus to the Lykian League on the Misbehavior of Soldiers. A New Inscription from Choma (Hacimusalar Höyük), Northern Lykia, Chiron 50, 2020, 253-285. 
Ritti 2002

Ritti 2017

Ritti et al. 2008

Robert 1935

Robert 1962

Robert 1983a

Robert 1983b

Rostovtzeff 1941

Roubineau 2012

Rousset 2002

Rousset 2019

Samitz 2013

Sänger 2010

Savalli-Lestrade 2018

Schuler 1998

Shaw 1984

Spagnuolo Vigorita 2012
T. Ritti, Documenti epigrafici dalla regione di Hierapolis, EA 34, 2002, 41-70.

T. Ritti, Hierapolis di Frigia IX. Storia e istituzioni di Hierapolis, Istanbul 2017.

Ritti et al., Museo Archeologico di Denizli-Hierapolis. Catalogo delle iscrizioni greche e latine, Distretto di Denizli, Napoli 2008.

L. Robert, Épigraphie grecque d'Asie Mineure, AC 4, 1935, 459-466 (= Id., Opera Minora Selecta, III, Amsterdam 1969, 1614-1621).

L. Robert, Villes d'Asie Mineure. Études de géographie ancienne, Paris $1962^{2}$.

J. Robert - L. Robert, Fouilles d'Amyzon en Carie, I, Exploration, histoire, monnaies et inscriptions, Paris 1983.

L. Robert, Les dieux des Motaleis en Phrygie, JS 1983, 45-63 (= Id., Opera Minora Selecta, VII, Amsterdam 1990, 549-567).

M. Rostovtzeff, The Social and Economic History of the Hellenistic World, 3 vols, Oxford 1941.

J.-M. Roubineau, La main cruelle de l'agoranome, in: L. Capdetrey

- Cl. Hasenohr (edd.), Agoranomes et édiles. Institutions des marchés antiques, Bordeaux 2012, 47-59.

D. Rousset, Le territoire de Delphes et la terre d'Apollon, Athènes 2002.

D. Rousset, Résumé des conférences et travaux 2017-2018. Épigraphie grecque et géographie historique du monde hellénique, Annuaire de l'École pratique des hautes études, Section des sciences historiques et philologiques 150, 2019, 113-122.

Chr. Samitz, Die Einführung der Dekaproten und Eikosaproten in den Städten Kleinasiens und Griechenlands, Chiron 43, 2013, 1-61.

Zur Organisation des Sicherheitswesens im kaiserzeitlichen Kleinasien und Ägypten. Rezension eines neuen Buches und komparative Studie zur Eirenarchie, Tyche 25, 2010, 99-122.

I. Savalli-Lestrade, Nouvelles considérations sur le dossier épigraphique de Toriaion (SEG 47. 1745 ; I. Sultan Dağı I, 393), ZPE 205, 2018, 165-177.

Chr. Schuler, Ländliche Siedlungen und Gemeinden im hellenistischen und römischen Kleinasien, München 1998.

B. D. Shaw, Bandits in the Roman Empire, P\&P 105, 1984, 3-52.

T. Spagnuolo Vigorita, Il latino della lex portus Asiae, in: M. Cassia et al. (edd.), Pignora amicitiae. Scritti di storia antica e storiografia offerti a Mario Mazza, II, Acireale - Roma 2012, 113-127. 
Speidel 1985

Takmer 2007

Thonemann 2011

Tziafalias - Lucas 2012

Uzunoğlu 2021

Virgilio 2001

Virgilio 2016

Weiss 1990

Weiss 2016

Weiss 2017

Weiss 2018

Wolff 2003

Wörrle 1979

Wörrle 1988

Yannakopulos 2003
M. P. Speidel, The Police Officer, a Hero. An Inscribed Relief from Near Ephesos (I.K. 17, 3222), EA 5, 1985, 159-160 (= Id., Roman Army Studies, II, Stuttgart 1992, 190-191).

B. Takmer, Lex Portorii Provinciae Lyciae: Ein Vorbericht über die Zollinschrift aus Andriake aus neronischer Zeit, Gephyra 4, 2007, 165-188.

P. Thonemann, The Maeander Valley. A Historical Geography from Antiquity to Byzantium, Cambridge 2011.

A. Tziafalias - G. Lucas, L'organisation de la surveillance du territoire de Dolichè, A

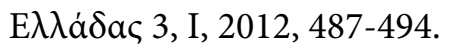

H. Uzunoğlu, Roman Soldiers and Imperial Properties in the Galatian-Phrygian Borderland: A New Inscription from the Eskişehir Museum, Gephyra 21, 2021, 65-89.

B. Virgilio, Su alcune concessioni attalidi a comunità soggette, in: B. Virgilio (ed.), Studi ellenistici XIII, Pisa - Roma 2001, 57-73.

B. Virgilio, La lettera di Filetero a Kyme Eolica e i decreti della città relativi a una fornitura di armamenti per la phylakè, in: B. Virgilio (ed.), Studi ellenistici XXX, Pisa - Roma 2016, 217-238.

P. Weiss, Marktgewichte von Kyzikos und Hipparchengewichte, in: E. Schwertheim (ed.), Mysische Studien, Bonn 1990, 117-139.

P. Weiss, Jenseits der Agoranomie. Neue und alte griechische Marktgewichte der Kaiserzeit, ZPE 200, 2016, 247-273.

P. Weiss, Der Hipparch Claudius Sellius Sulla und Sellius Sulla, der Asiarch und Rhetor, ZPE 203, 2017, 142-143.

P. Weiss, Jenseits der Agoranomie II. Ein weiteres Gewicht eines Eirenarchenpaares von Kolophon. Mit Nachträgen zu Hipparchengewichten, ZPE 206, 2018, 135-139.

C. Wolff, Les brigands en Orient sous le Haut-Empire romain, Rome 2003.

M. Wörrle, Epigraphische Forschungen zur Geschichte Lykiens III: Ein hellenisticher Königsbrief aus Telmessos, Chiron 9, 1979, 83-111.

M. Wörrle, Stadt und Fest im kaiserzeitlichen Kleinasien. Studien zu einer agonistischen Stiftung aus Oinoanda, München 1988.

N. Yannakopulos, Preserving the Pax Romana: The Peace Functionaries in Roman East, MediterrAnt 6, 2003, 825-905. 


\section{Helenistik ve Roma İmparatorluk Dönemi Küçük Asya’sında Kırsalı Korumak: Yönetim, Finansman ve Vergilendirme \\ Özet}

Bu makale, son on beş yılda yayımlanan bir düzine yeni yazıttan faydalanarak, Hellenistik ve Roma İmparatorluk Dönemi Küçük Asya’sındaki Yunan kentlerinde kırsalı korumanın (phylake tes choras) idari, mali ve finansal boyutlarını incelemektedir. Kırsal alanların güvenliğini sağlamakla ilgilenen daimî kurumların yokluğu ve nakit para sıkıntısı yüzünden Hellenistik kentler ve bazen de bizzat krallar böyle bir hizmeti oluşturmak ve finanse etmek için değişik ve kompleks çözümler bulmaya mecbur kalıyorlardı. Bunlar kırsal yerleri muhafaza edecek yerleşim sakinlerine vergi muafiyeti verilmesi, ödeme karşllı̆̆nda güvenlik işini üstlenecek özel kişileri kontrat ile işe alma ya da kendilerini finanse etsinler diye vergi toplama izni verilen aracilar vasitasıyla bu hizmeti kiraya vermeyi kapsamaktaydı. Thessalia'dan yakın zamanda yayımlanan bir yazıt ve aynı zamanda Polyainos'un Strategemata isimli eserinden bir alıntı sayesinde, bu makale Miletos ve Herakleia arasında müttefiklik anlaşmasında yer alan bu konuyla ilgili hükümleri yeniden değerlendirmekte ve muhafızların vergi toplama işine gerçekte ne derece dahil olduğu sorusunu sormaktadır. İmparatorluk Dönemi’nde tüm Küçük Asya eyaletlerinde paraphylakes adıyla bilinen görevliler kırsaldaki kamu güvenliğiyle ilgilenmeleri için kentler tarafından atanıyorlardı. Özellikle Phrygia'daki Hierapolis olmak üzere Küçük Asya'daki değişik kentlerden yayımlanan yeni belgeler koruma ve kollama işinin finansmanı, paraphylakes'in ekonomik görevleri ve aynı zamanda bağışların kırsal topluluklar üzerindeki etkisi ve bu memurların görevlerini kötüye kullanmaları hakkında yeni bilgiler vermektedir. Bu makale, her ne kadar kırsalda aktif olsalar da hemen hemen aynı zamanda, İ.S. 1. yüzyılda ortaya çıkan dekaprotoi'un aksine paraphylakes' in vergi toplamadan sorumlu olmadığını iddia etmektedir. Her ne kadar Roma eyalet idaresi, yerel düzeyde yasaların uygulanması ve vergi toplama işiyle ilgili olarak bu iki görevliye bel bağlasa da bunlar Roma gücü tarafından oluşturulmamıştır ve daha çok imparatorluk yönetimi altında Yunan kentlerinin keyfini sürdüğü otonominin bir diğer kanıtı olarak görülmelidir.

Anahtar Sözcükler: Koruma ve kollama, kırsal, kırsal nüfus, finansman, vergilendirme, kentler, yerel memurlar.

\section{Patrolling the Countryside in Hellenistic and Imperial Asia Minor: Administration, Funding, and Taxation}

Abstract

Drawing on the publication of a dozen of new inscriptions during the past fifteen years, the article examines the administrative, financial and fiscal implications of patrolling the countryside ( $p h y$ lake tes choras) in Greek cities of Asia Minor during the Hellenistic and Roman Imperial periods. Due to the lack of permanent institutions dealing with the policing of their rural territories and because of cash shortage, Hellenistic cities, and sometimes kings themselves, were forced to find various and complex solutions to set up and fund such a service. These included the granting of tax exemptions to inhabitants of rural settlements policing the countryside, the hiring under contract of private persons who would take care of patrolling in exchange for payment, or the leasing of the service by contractors who would be allowed to collect taxes in order to refund themselves. Thanks to a recently published inscription from Thessaly as well as a passage from Polyaenus' Stratagems, the paper reassesses the provisions related to this issue included in the alliance treaty 
between Miletos and Herakleia and raises the question as to the extent to which guards were actually involved with tax collection. During the Imperial period, officials known as paraphylakes were appointed by cities throughout the provinces of Asia Minor to deal with public security in the countryside. Newly published evidence from various cities of Asia Minor, in particular from Phrygian Hierapolis, sheds new light on the funding of patrolling, on the economic duties of paraphylakes, as well as on the impact on rural communities of the benefactions, as well as of the abuses, of these officials. The paper argues that, although they were active in the countryside, paraphylakes were not responsible for the collection of taxes, contrary to dekaprotoi, who emerged about the same time during the first century CE. Even if Roman provincial administration relied on these two offices as far as law enforcement and tax collection at the local level were concerned, they were not created by Roman power and should rather be seen as another proof of the autonomy Greek cities enjoyed under imperial rule.

Keywords: policing, countryside, rural population, funding, taxation, cities, local officials. 